\title{
Dinâmica da polarização da oferta de trabalho familiar no Brasil urbano
}

\author{
Dynamics of the polarization of family labor supply in urban Brazil
}

\begin{abstract}
This article explores different dimensions of the family labor supply in Brazil in relation to changes in family arrangements in recent decades. Specifically, the dynamics of the polarization of family labor supply between 1993 and 2015 in urban Brazil is investigated using microdata from the National Household Sample Survey (PNAD). The risk factors associated with the highest individual probability of living in a jobless family are estimated based on multinomial logistic regressions, for the odds of being in a family where: no adult works, or all adults work, or only a fraction of them works. The results show that the composition of families is determinant in the complexity of jobless families, with child and elderly dependence ratios on families being directly related to the increasing risks of being in a family without work over the period, especially for women.
\end{abstract}

\section{Keywords}

labor supply, family structures, polarization, Brazil.

JEL Codes J20, J12, C35.

\author{
Danyella Juliana Martins de Brito (1) \\ Ana Maria Hermeto Camilo de Oliveira (2) \\ (1) Universidade Federal de Pernambuco \\ (2) Universidade Federal de Minas Gerais
}

\section{Resumo}

$O$ artigo explora diferentes dimensões da oferta de trabalho familiar no Brasil em sua relação com as mudanças dos arranjos familiares. Especificamente, a dinâmica da polarização da oferta de trabalho familiar entre 1993 e 2015 no Brasil urbano é investigada utilizando os microdados da Pesquisa Nacional por Amostra de Domicilios (PNAD). São estimados os fatores de risco associados à maior probabilidade individual de viver em uma familia sem trabalho a partir de regressões logísticas multinomiais, para as chances de estar numa familia em que: nenhum adulto trabalha, ou todos os adultos trabalham, ou somente uma fração dos adultos trabalha. Os resultados apontam que a composição das famílias é determinante na complexidade dos agregados familiares sem trabalho, estando as razões de dependência infantil e de idosos das famílias diretamente relacionadas com riscos crescentes de estar numa familia sem trabalho ao longo dos anos, sobretudo para as mulheres.

\section{Palavras-chave}

oferta de trabalho, estruturas familiares, polarização, Brasil.

Códigos JEL J20, J12, C35. 


\section{Introdução}

Diante de um contexto de acelerado processo de transição demográfica, que tem repercussões sobre a evolução composicional das famílias no Brasil, buscou-se neste artigo avançar sobre a análise da diversidade da oferta de trabalho familiar ao longo do tempo. Especificamente, busca-se responder às questões relativas à compreensão das mudanças nos padrões de formação familiar em sua associação com as alterações dos condicionantes da polarização da oferta de trabalho familiar nas últimas décadas.

Gregg e Wadsworth (1996) trouxeram para discussão acadêmica a questão da crescente polarização entre os domicílios "ricos em trabalho" e aqueles "pobres em trabalho", avançando em relação às estatísticas de desemprego baseadas no indivíduo para a distribuição do desemprego entre os domicílios. A importância desse tipo de análise está associada ao que Gregg e Wadsworth (2001; 2002; 2008) e Gregg et al. (2010) definem como taxa de não trabalho de uma sociedade, entendida como a proporção de indivíduos inativos e desempregados da população total. Esses autores enfatizam a importância de se pensar essa taxa pela perspectiva individual e familiar através de um modelo simplificado do mundo real, em que existem apenas duas famílias e dois indivíduos em cada uma delas. Nesse cenário, supondo uma taxa de não trabalho de $50 \%$ da população, o mundo em que um indivíduo em cada domicílio possui trabalho será bem diferente daquele em que ambos os trabalhadores pertencem unicamente a um domicílio, especialmente no que tangencia a pobreza e desigualdade nessa sociedade (Gregg et al., 2010). A análise por uma ótica domiciliar é especialmente importante para aplicação de políticas públicas voltadas para o mercado de trabalho e combate à pobreza, que visem melhor distribuição dos postos de emprego.

Este artigo se propõe a estimular esta discussão relevante e pouco explorada no contexto brasileiro, posto que o aumento da concentração de empregos assalariados no nível domiciliar apresenta novos desafios para condutores e elaboradores de política social. A importância da ponderação dos custos sociais dos agregados familiares sem trabalho deve partir da compreensão dos fatores associados aos riscos de viver em uma família sem trabalho. $O$ objetivo deste artigo é, portanto, analisar a polarização da oferta de trabalho familiar no contexto das recentes mudanças demográficas e econômicas que a sociedade brasileira enfrenta. As principais 
questões abordadas são: qual é o contexto do desemprego nas famílias? O que é um agregado familiar sem trabalho? O Brasil tem uma alta proporção de domicílios sem trabalho? Caso sim, por qual razão? Quais são as características gerais e onde está concentrada a maior parte das famílias sem trabalho no Brasil urbano? E quais os fatores que elevam as chances individuais de estar num agregado familiar desse tipo ao longo dos anos? Ademais, os resultados podem indicar se a taxa de domicílios sem trabalho no Brasil é cíclica ou se contém um elemento estrutural. Compreendendo tais questões fundamentais torna-se possível avançar na discussão de quais são as respostas necessárias de políticas públicas para a redução das taxas de não trabalho familiar ${ }^{1}$.

Este artigo está dividido em quatro seções, além desta introdução. $\mathrm{Na}$ próxima seção é situado o debate atual teórico e empírico sobre a polarização da oferta de trabalho familiar. Na terceira seção, o conceito de polarização da oferta de trabalho familiar é definido pela estratégia empírica, em termos da organização dos dados e variáveis e dos métodos de estimação. Na quarta seção são calculados os indicadores de polarização do trabalho entre as famílias e é estimado o risco de estar numa família sem trabalho ou numa família com trabalho por meio de modelos logit multinomiais. Os resultados são apresentados enfatizando as mudanças das famílias ao longo do tempo. De modo geral, é possível afirmar que o aumento da diferença entre as medidas de não trabalho individual e familiar é reflexo de mudanças na composição das famílias e mudanças na distribuição do emprego entre as famílias. As modificações na composição das famílias, por sua vez, estão intimamente relacionadas aos processos de transição demográfica e de alterações na composição da força de trabalho por sexo e idade. Na última seção são indicados os apontamentos conclusivos extraídos dos resultados.

\section{0 debate teórico e empírico sobre a polarização da oferta de trabalho familiar}

O conceito de polarização da oferta de trabalho familiar foi desenvolvido por Gregg e Wadsworth (2001; 2002; 2008) e Gregg et al. (2010) como a

1 Os termos "taxa de não trabalho familiar" e "taxa de famílias sem trabalho" são tratados como sinônimos. 
proporção de domicílios sem trabalho que seria observada se o emprego fosse aleatoriamente distribuído na população, isto é, entre os domicílios. Os autores propõem um índice que pode ser usado para mensurar a extensão e as fontes de divergência entre as taxas de não trabalho calculadas aos níveis individuais e domiciliares, em uma sequência de estudos aplicados em distintas localidades. Tal índice é construído em torno de uma comparação da proporção de domicílios sem trabalho com aquela que ocorreria caso o trabalho fosse igualmente distribuído. Um domicílio é considerado sem trabalho se nenhum adulto residente está trabalhando, ${ }^{2}$ ou seja, se todos os membros estão desempregados ou inativos. As taxas de famílias sem trabalho, quando elevadas ou crescentes, estão diretamente associadas a sérios problemas que afetam o bem-estar social, tais como vulnerabilidade à pobreza, desigualdade de renda e a transmissibilidade intergeracional da pobreza. A comparação da experiência em termos da oferta de trabalho familiar de diferentes grupos dentro da população pode levar a explicações coerentes para as tendências de desigualdade de renda no país. A taxa de não trabalho individual (proporção de desempregados e inativos em idade ativa do total da população em idade ativa) e a proporção de famílias nas quais ninguém trabalha podem ser muito diferentes em uma sociedade. Consequentemente, o padrão de emprego em certos países pode tornar-se, cada vez mais, distribuído de forma desigual entre as famílias em idade ativa (Gregg; Wadsworth, 1996; 1998).

Segundo Gregg et al. (2010), uma polarização negativa do trabalho caracterizada por menos famílias sem trabalho do que o esperado se o emprego fosse alocado aleatoriamente - pode apresentar uma estreita relação com as teorias de gênero sobre a divisão do tempo de não trabalho e de trabalho. As abordagens teóricas de Danziger e Katz (1996) e François (1998) enfatizam as atitudes sociais em relação à discriminação sexual no mercado de trabalho, sugerindo que tal discriminação gera custos e benefícios, sendo uma parte considerável desses custos atenuada pela divisão entre os casais. Nesse sentido, mulheres e homens se organizam em agregados familiares, e, quando as características do mercado de trabalho (esforço e salários) diferem, surge a possibilidade de benefício mútuo em trocas dentro do domicílio em termos de horas dedicadas às atividades domiciliares e de lazer. Com base nessas perspectivas, é possível que, em

2 Trabalho definido como ocupação produtiva no mercado de trabalho. 
sociedades mais tradicionais, nas quais haja predominância de famílias de único provedor masculino, seja notável o número de famílias de dois adultos em que apenas o homem trabalha, o que conduziria a uma medida de polarização negativa.

Diversos estudos replicaram a construção dos índices de polarização para diferentes países, encontrando resultados distintos, com taxas de polarização negativas, crescentes ou decrescentes ao longo do tempo, bem como diferentes fatores que afetam a probabilidade de os indivíduos, desempregados e ocupados, residirem em domicílios sem trabalho. Para os países da Organização para a Cooperação e o Desenvolvimento Econômico (OCDE), Gregg et al. (2010) verificaram aumento da desigualdade na distribuição de trabalho, ou seja, crescente polarização do trabalho, quantificando a extensão das disparidades decorrentes das medidas individuais e domiciliares de falta de trabalho para países com diferentes níveis de emprego, de estrutura familiar e de apoio social - Grã-Bretanha, Espanha, Estados Unidos, Austrália e Alemanha -, em um período de 25 anos. Köksel et al. (2016) analisaram as famílias com indivíduos jovens desempregados (de 15 a 29 anos) em vários países. Corluy e Vandenbroucke (2013) e Köksel (2017) analisaram uma faixa etária mais ampliada, estimando fatores de risco associados a maior probabilidade de viver em domicílios sem trabalho ou com baixa intensidade de trabalho. Gregg e Wadsworth (1996) e Lehmann e Wadsworth (1997) estimaram a probabilidade de transição do desemprego-inatividade para a ocupação, considerando características dos domicílios, e relacionando tal probabilidade com a ocorrência de domicílios sem trabalho. Nolen (2013) constatou que indivíduos desempregados que vivem em famílias em que pelo menos uma pessoa trabalha possuem mais chances de transitarem para o emprego, comparativamente àqueles desempregados residentes em domicílios nos quais todos os membros estão na mesma situação.

A literatura aponta a existência de vários fatores diferentes que podem estar relacionados com a crescente concentração do número de adultos sem trabalho em alguns domicílios. Esses fatores incluem: os padrões de casamento, em que os indivíduos com maiores chances de ficarem sem trabalho tendem também a encontrar parceiros com baixas perspectivas de empregabilidade; as alterações na composição das famílias, por exemplo, o número crescente de famílias unipessoais, entre as quais a incidência do desemprego ou inatividade é mais elevada; a presença de crianças 
e idosos; e mudanças no mercado de trabalho local (Gregg; Wadsworth, 2001; 2002; 2008; Singley; Callister, 2003; Gregg et al., 2010; NESC, 2014).

Alguns estudos enfatizam os efeitos da polarização do trabalho e, por conseguinte, da renda sobre as famílias com crianças, tais como Dawkins et al. (2002) e Gregg et al. (2017). Nesse último, os autores examinam a relação entre viver numa família sem trabalho na infância e três resultados: educação, emprego na vida adulta e pobreza na vida adulta. Eles estimam uma série de modelos de probabilidade intergeracionais e constatam que as consequências negativas de pertencer a uma família sem trabalho sobre os custos de bem-estar e aumento do risco de pobreza e sobre as oportunidades futuras das crianças são profundas.

O elevado número de famílias com todos os adultos empregados ou com todos os adultos sem emprego é um fenômeno que necessita ser mais amplamente compreendido, uma vez que a proporção de famílias sem trabalho é uma medida importante de exclusão social. Para o contexto brasileiro somente o estudo de Scorzafave e Menezes-Filho (2007) analisa a polarização do trabalho entre domicílios no Brasil para o período de 1981 a 2003 e aponta que houve polarização do emprego negativa, porém crescente. Os autores usam a mesma abordagem metodológica de Gregg e Wadsworth (1996; 1998; 2001; 2002) e Gregg et al. (2010).

\section{Metodologia}

\subsection{Estratégia empírica de mensuração da polarização da oferta de trabalho familiar e seus determinantes no Brasil}

Conforme a definição de polarização da oferta de trabalho familiar proposta por Gregg e Wadsworth (2001; 2002; 2008) e Gregg et al. (2010), todos os indivíduos residentes de uma determinada região apresentam a mesma probabilidade de não estarem trabalhando, representada por aquilo que os autores denominam de taxa agregada de não trabalho da população, $n$. Essa taxa engloba a proporção de inativos e desempregados no tempo $t$. A taxa prevista de não trabalho em uma família com $k$ adultos residentes na família no período $t$ é:

$$
p_{k t}=n_{t}^{k}
$$


Nesse caso, a probabilidade prevista de observar uma família de um adulto sem trabalho é igual à taxa de não trabalho individual, a probabilidade de uma família com dois adultos sem trabalho será o quadrado da taxa de não trabalho individual, e assim sucessivamente para famílias maiores (a probabilidade aumenta de maneira exponencial). ${ }^{3}$ A taxa contrafactual de famílias sem trabalho, prevista por uma distribuição aleatória dos empregos entre os indivíduos, é dada por:

$$
\hat{W}=\sum_{k=1}^{K} s_{k} p_{k}=\sum_{k=1}^{K} s_{k} n^{k}
$$

Desse modo, o conceito de polarização da oferta de trabalho é a diferença entre a taxa familiar de não trabalho efetivamente observada (w), isto é, a proporção de famílias em que todos os membros adultos não possuem trabalho, e a taxa prevista $(\hat{w})$ :

$$
\text { Polarização }=\mathfrak{w}-\hat{w}=\sum_{k=1}^{K} s_{k} \mathfrak{w}_{k}-\sum_{k=1}^{K} s_{k} n^{k}=\sum_{k=1}^{K} s_{k}\left(w_{k}-n^{k}\right)
$$

Essa expressão é uma medida da diferença (em pontos porcentuais) entre as taxas de não trabalho calculadas com base na família e no indivíduo, tal que $w_{k}$ é a proporção de famílias com $k$ adultos em que todos eles estão inativos ou desempregados. Quanto maior a polarização, maior é a proporção de famílias sem trabalho em relação ao previsto por uma distribuição aleatória do trabalho na população. Caso a taxa de famílias sem trabalho observada seja igual à taxa prevista, o emprego é aleatoriamente distribuído e a taxa de polarização é zero. Uma taxa de polarização negativa indica que o trabalho tal como é distribuído gera menos famílias sem trabalho do que seria observado caso as vagas fossem distribuídas aleatoriamente entre os indivíduos.

Gregg et al. (2010) decompõem a variação na taxa de famílias sem trabalho prevista, $\hat{w}$, entre o período final e inicial de observação em dois efeitos: o impacto da mudança na taxa de não trabalho individual observada ao longo do tempo (segundo termo da equação 3.1); e o efeito da mudança na composição domiciliar, em termos de número de adultos, ao longo do

3 Gregg e Wadsworth $(2001 ; 2002)$ ressaltam que a taxa prevista de não trabalho domiciliar é um contrafactual e que, quando ignorado o subscrito de tempo, a taxa prevista de não trabalho agregada é uma média ponderada dessas taxas domiciliares em que os pesos são as parcelas de cada tipo de família na população, definido empiricamente pela proporção de famílias de tamanho $k\left(s_{k}\right)$. 
tempo (primeiro termo da equação 3.1). Portanto, a variação na taxa de famílias sem trabalho prevista pode ser decomposta como:

$$
\begin{aligned}
& \Delta \hat{\mathcal{W}}=\sum_{k=1}^{K} \Delta\left\{s_{k} n^{k}\right\} \\
& =\sum_{k=1}^{K} \Delta s_{k}\left[0,5 n_{t}^{k}+0,5 n_{t+1}^{k}\right]+\sum_{k=1}^{K} \Delta n^{k}\left[0,5 s_{k, t}+0,5 s_{k, t+1}\right]
\end{aligned}
$$

A decomposição ao longo do tempo da variação na polarização é:

$$
\begin{aligned}
& \left(w_{t+1}-\hat{w}_{t+1}\right)-\left(w_{t}-\hat{w}_{t}\right)=\Delta(w-\hat{w})=\sum_{k=1}^{K} \Delta\left\{s_{k}\left(w_{k}-n^{k}\right)\right\} \\
& =\sum_{k=1}^{K} \Delta s_{k}\left[0,5\left(w_{k}-n^{k}\right)_{t}+0,5\left(w_{k}-n^{k}\right)_{t+1}\right] \\
& +\sum_{k=1}^{K} \Delta\left(w_{k}-n^{k}\right)\left[0,5 s_{k, t}+0,5 s_{k, t+1}\right]
\end{aligned}
$$

$\mathrm{Na}$ equação 3.2 , o primeiro termo na segunda linha refere-se ao efeito da alteração nos tipos de famílias, essencialmente em termos de número de adultos, mantendo a polarização constante no valor médio dos dois períodos, o que pode ser entendido como um efeito entre grupos; e o segundo termo da equação na terceira linha está associado a mudança ocorrida dentro das famílias, mantendo a composição dos tipos de famílias constante no valor médio dos dois períodos - esse último efeito, por sua vez, pode ser compreendido como um efeito dentro dos grupos. Uma vez que a mudança na taxa de famílias sem trabalho é $\Delta w=\Delta \hat{w}+\Delta(w-\hat{w})$, temos:

$$
\begin{aligned}
& \Delta w=\Delta \hat{w}+\Delta(w-\hat{w})=\sum_{k=1}^{K} \Delta\left\{s_{k} n^{k}\right\}+\sum_{k=1}^{K} \Delta\left\{s_{k}\left(w_{k}-n^{k}\right)\right\} \\
& =\sum_{k=1}^{K} \Delta s_{k}\left[0,5 n_{t}^{k}+0,5 n_{t+1}^{k}\right]+\sum_{k=1}^{K} \Delta n^{k}\left[0,5 s_{k, t}+0,5 s_{k, t+1}\right] \\
& +\sum_{k=1}^{K} \Delta s_{k}\left[0,5\left(w_{k}-n^{k}\right)_{t}+0,5\left(w_{k}-n^{k}\right)_{t+1}\right] \\
& +\sum_{k=1}^{K} \Delta\left(w_{k}-n^{k}\right)\left[0,5 s_{k, t}+0,5 s_{k, t+1}\right]
\end{aligned}
$$

O primeiro termo se refere à contribuição da mudança na taxa de famílias sem trabalho predita devido a mudanças nas proporções de famílias por número de adultos e devido a alterações nas taxas de não trabalho; o terceiro e o quarto termos são as medidas de polarização entre e dentro das 
famílias, respectivamente. O efeito da alteração nos tipos de famílias mostra, por exemplo, se um aumento da polarização ocorre em decorrência de um aumento na proporção de famílias com menores chances de ter todos os membros ocupados. O efeito da alteração ocorrida dentro das famílias fornece, por exemplo, a contribuição de uma piora das condições gerais de emprego para todos os tipos de famílias (Gregg; Wadsworth, 2001).

Distinguindo as famílias "sem trabalho" daquelas "ricas em trabalho", em que todos os membros adultos estão ocupados no mercado de trabalho, por meio de um modelo logit multinomial torna-se possível modelar a probabilidade de viver em uma família em que ninguém trabalha. $\mathrm{Na}$ medida em que são consideradas as características familiares em tais modelos, estamos analisando a ocorrência dessas famílias sem trabalho à luz das mudanças demográficas que se refletem no aumento da diversidade dos tipos de família. Com isso, espera-se obter melhor compreensão de quem são os indivíduos que se defrontam com um alto risco de viver nesses tipos de família ao longo dos anos. Nesses modelos de regressão a variável dependente é categórica: vive numa família em que nenhum adulto trabalha (1); vive numa família em que todos os adultos trabalham (2); e vive numa família em que pelo menos um adulto trabalha, mas não todos (3). Logo, têm-se $j=1,2,3$ situações e $i=1,2, \ldots, N$ indivíduos. $O$ previsor linear para o indivíduo $i$ é dado por $X_{i} \beta_{j}$, tal que, o logit multinomial modela a probabilidade de o indivíduo $i$ estar na situação $j$ como:

$$
P\left(Y_{i}=j\right)=P_{i j}=\frac{\exp \left(X_{i} \beta_{j}\right)}{1+\sum_{j=1}^{2} \exp \left(X_{i} \beta_{j}\right)}, \quad j=1,2
$$

$\mathrm{Na}$ expressão anterior, $X_{i}$ é o vetor de características individuais, familiares e regionais do indivíduo $i$. A soma no denominador assegura que a soma das probabilidades das opções de resposta é igual a 1. Foram utilizados como categoria base os indivíduos adultos que estão em famílias nas quais pelo menos um adulto está empregado (categoria 3).

\subsection{Dados e variáveis}

Para os objetivos de mensurar a polarização no Brasil urbano e identificar os fatores de risco associados à probabilidade de viver em uma família em 
que nenhum adulto trabalha, são utilizados os microdados da Pesquisa Nacional por Amostra de Domicílios/Instituto Brasileiro de Geografia e Estatística (PNAD/IBGE), para o período de 1993 a 2015. São considerados os indivíduos com idade entre 18 e 65 anos de idade, residentes da área urbana, ${ }^{4}$ e são excluídos os domicílios em que todos os adultos eram inativos e que a única fonte de rendimento era aposentadoria ou pensão. São excluídos os domicílios com famílias conviventes, já que, caso dentro de um domicílio haja uma família totalmente desempregada ou inativa, mas haja outra pessoa/família residente trabalhando, gerando renda, é possível que ocorra um fluxo intradomiciliar de rendimento entre as duas famílias (estes correspondem a 13,51\% em 1993 e 8,74\% em 2015). O cálculo das medidas de não trabalho e polarização envolve, portanto, exclusivamente indivíduos adultos (entre 18 e 65 anos) e famílias de $k$ adultos com ou sem crianças residentes.

A fim de observar os fatores de risco que elevam as probabilidades individuais de estar em uma família em que todos os adultos trabalham e de estar em uma família em que nenhum adulto trabalha, as variáveis independentes que refletem as características observáveis, possivelmente relacionadas às chances de um indivíduo estar numa família sem trabalho no modelo logit multinomial, são expostas no Quadro 1. Seguindo a literatura, as estimativas são conduzidas separadamente por sexo, pois os fatores de risco que elevam as probabilidades individuais de estar em uma família sem trabalho devem ser distintos para homens e mulheres também no Brasil (Köksel et al., 2016; Köksel, 2017).

Quadro 1 Variáveis possivelmente relacionadas com a variável dependente: status ocupacional familiar - PNAD (1993-2015)

\begin{tabular}{|c|c|}
\hline Variáveis independentes & Referências \\
\hline \multicolumn{2}{|l|}{ Individuais } \\
\hline $\begin{array}{l}\text { Idade (grupos trianuais de idade) } \\
\text { Escolaridade ( } 1 \text { = sem escolaridade ou menos } \\
\text { de } 3 \text { anos de estudo, } 2 \text { = de } 4 \text { a } 7 \text { anos de estudo, } \\
3=\text { de } 8 \text { a } 10 \text { anos de estudo, } 4 \text { = de } 11 \text { a } 14 \text { anos } \\
\text { de estudo, } 5 \text { = de } 15 \text { ou mais anos de estudo) }\end{array}$ & $\begin{array}{l}\text { Corluy; Vandenbroucke (2013); Köksel et al. } \\
\text { (2016); Köksel (2017); Gregg; Wadsworth } \\
\text { (2001; 2002; 2008); Gregg et al. (2010); } \\
\text { Scorzafave; Menezes-Filho (2007) }\end{array}$ \\
\hline
\end{tabular}

(continua)

4 Dada a complexidade do desenho amostral da PNAD, foi considerado o fator de expansão (peso amostral), quanto à declaração do plano amostral (Pessoa; Silva, 1998; Silva et al., 2002, Vieira et al., 2016). 
Quadro 1 (continuação)

\begin{tabular}{|c|c|}
\hline Variáveis independentes & Referências \\
\hline $\begin{array}{l}\text { Migrante intermunicipal nos últimos } 10 \text { anos } \\
(1=\operatorname{sim}, 0=\text { não })\end{array}$ & Corluy; Vandenbroucke (2013) \\
\hline \multicolumn{2}{|l|}{ Domiciliares/Familiares } \\
\hline $\begin{array}{l}\text { Tamanho da família (a) } \\
\text { Razão de dependência familiar para crianças (b) } \\
\text { Razão de dependência familiar para idosos (b) } \\
\text { Família cuja responsável é mulher ( } 1=\operatorname{sim}, 0 \text { = não) }\end{array}$ & $\begin{array}{l}\text { Gregg; Wadsworth (2001; 2002); Gregg et al. } \\
\text { (2010); Scorzafave; Menezes-Filho (2007); } \\
\text { Corluy; Vandenbroucke (2013); Köksel et al. } \\
\text { (2016); Köksel (2017) }\end{array}$ \\
\hline
\end{tabular}

\section{Regionais}

Residente de região metropolitana (1 = sim, 0 = não) Gregg; Wadsworth (2001; 2002); Gregg et al. Região de residência $(1=$ Sudeste, $2=$ Norte,

$3=$ Nordeste, $4=$ Sul, 5 = Centro-Oeste) (2010); Scorzafave; Menezes-Filho (2007); Köksel et al. (2016); Köksel (2017)

Fonte: Elaboração própria.

Notas: (a) Engloba o total de residentes no domicílio da família de análise, considerando crianças, adultos e idosos. (b) As razões de dependência são definidas como o peso da população inativa (0 a 14 anos e 65 anos e mais de idade, separadamente) sobre a população potencialmente ativa (15 a 64 anos de idade) para cada família.

\section{Evolução dos arranjos familiares e da oferta de trabalho familiar no Brasil: estatísticas descritivas e resultados}

\subsection{Caracterização dos indivíduos, das famílias e da distribuição de trabalho nas famílias}

Para contextualizar o processo de transição demográfica brasileira segundo as mudanças na composição das famílias, dos tamanhos das famílias e da participação dos casais na força de trabalho, conforme apontado por Wajnman (2012) e Bilac (2014), incialmente são analisadas a composição e a organização econômica das famílias exclusivamente compostas por casais no Brasil urbano entre 1993 e 2015. A Tabela 1 mostra a proporção de famílias para cada tipo de organização econômica entre casais, assumindo a definição de organização econômica desses casais de acordo com Ruggles (2015), segundo a qual uma família é de duplo provedor se ambos trabalham; se apenas a mulher ou somente o homem está inserido no mercado de trabalho, a família é definida como de provedor feminino ou masculino, respecti- 
vamente. Acrescentam-se as categorias casal desempregado e casal inativo.

Tabela 1 Distribuição das famílias de casais por organização econômica, Brasil urbano, 1993-2015 (\%)

\begin{tabular}{lr|r|r|r|r|r|r|r|r}
\hline & $\mathbf{1 9 9 3}$ & $\mathbf{1 9 9 6}$ & $\mathbf{1 9 9 9}$ & $\mathbf{2 0 0 2}$ & $\mathbf{2 0 0 5}$ & $\mathbf{2 0 0 8}$ & $\mathbf{2 0 1 1}$ & $\mathbf{2 0 1 4}$ & $\mathbf{2 0 1 5}$ \\
\hline Duplo provedor & 43,0 & 43,2 & 45,2 & 48,3 & 51,3 & 53,5 & 52,6 & 54,6 & 51,5 \\
\hline Homem provedor & 48,1 & 46,6 & 44,4 & 41,2 & 38,0 & 36,1 & 36,9 & 34,3 & 35,2 \\
\hline Mulher provedora & 3,7 & 4,7 & 4,8 & 5,2 & 5,4 & 5,4 & 5,2 & 6,0 & 7,3 \\
\hline Casal desempregado & 0,3 & 0,4 & 0,7 & 0,5 & 0,5 & 0,3 & 0,3 & 0,3 & 0,6 \\
\hline Casal inativo & 5,0 & 5,1 & 5,0 & 5,0 & 4,9 & 4,8 & 5,0 & 4,9 & 5,4 \\
\hline
\end{tabular}

Fonte: Elaboração própria, a partir dos microdados da PNAD, 1993-2015.

Destaca-se que a proporção de casais tradicionais, de principal provedor homem, deixa de ser prevalente, caindo de 48,1\% em 1993 para 35,2\% em 2015. Ao mesmo tempo, passam a prevalecer os casais de duplo provedor, cuja proporção cresce de $43 \%$ para $51,5 \%$, e aumenta significantemente a proporção de casais de único provedor feminino, de $3,7 \%$ para $7,3 \%$.

Considerando na Tabela 2 a amostra mais abrangente de estruturas familiares, que engloba unipessoais, monoparentais, casais com e sem filhos, são apresentados o tamanho médio das famílias e as proporções de famílias de responsabilidade feminina. Prevalecem ao longo de todo o período as famílias de principal responsável homem, porém é acentuado o crescimento do número de famílias em que as mulheres são as principais responsáveis. Na Tabela 3 verifica-se, entre as famílias com mulheres responsáveis, a elevada proporção de famílias monoparentais e o forte crescimento da proporção de famílias de casais com e sem filhos.

Tabela 2 Proporção de famílias de responsabilidade feminina e tamanho médio das famílias por sexo do principal responsável, Brasil urbano, 1993-2015 (\%)

\begin{tabular}{l|c|c|c|c|c|c|c|c|c}
\hline & $\mathbf{1 9 9 3}$ & $\mathbf{1 9 9 6}$ & $\mathbf{1 9 9 9}$ & $\mathbf{2 0 0 2}$ & $\mathbf{2 0 0 5}$ & $\mathbf{2 0 0 8}$ & $\mathbf{2 0 1 1}$ & $\mathbf{2 0 1 4}$ & $\mathbf{2 0 1 5}$ \\
\hline $\begin{array}{l}\text { \% Responsáveis } \\
\text { mulheres }\end{array}$ & 18,2 & 20,2 & 21,8 & 23,8 & 26,7 & 33,5 & 36,1 & 38,9 & 39,8 \\
\hline $\begin{array}{l}\text { Tamanho médio } \\
\text { das famílias }\end{array}$ & & & & & & & & & \\
\hline Mulher responsável & 3,04 & 3,04 & 2,94 & 2,92 & 2,88 & 2,98 & 2,97 & 2,88 & 2,88 \\
\hline Homem responsável & 4,03 & 3,94 & 3,79 & 3,65 & 3,51 & 3,37 & 3,25 & 3,11 & 3,08 \\
\hline
\end{tabular}

Fonte: Elaboração própria, a partir dos microdados da PNAD, 1993-2015. 
Tabela 3 Distribuição dos tipos de família por sexo do principal responsável, Brasil urbano, 1993-2015 (\%)

\begin{tabular}{|c|c|c|c|c|c|c|c|c|}
\hline \multirow[t]{2}{*}{ Ano } & \multicolumn{4}{|r|}{ Mulher } & \multicolumn{4}{|r|}{ Homem } \\
\hline & $\begin{array}{r}\text { Uni- } \\
\text { pessoal }\end{array}$ & $\begin{array}{r}\text { Casal } \\
\text { sem } \\
\text { filhos }\end{array}$ & $\begin{array}{r}\text { Casal } \\
\text { com } \\
\text { filhos }\end{array}$ & $\begin{array}{r}\text { Mono- } \\
\text { parental }\end{array}$ & $\begin{array}{r}\text { Uni- } \\
\text { pessoal }\end{array}$ & $\begin{array}{r}\text { Casal } \\
\text { sem } \\
\text { filhos }\end{array}$ & $\begin{array}{r}\text { Casal } \\
\text { com } \\
\text { filhos }\end{array}$ & $\begin{array}{r}\text { Mono- } \\
\text { parental }\end{array}$ \\
\hline 1993 & 24,3 & 1,9 & 5,2 & 68,6 & 6,4 & 15,8 & 76,4 & 1,5 \\
\hline 1996 & 24,4 & 3,1 & 8,3 & 64,3 & 6,6 & 16,3 & 75,5 & 1,6 \\
\hline 1999 & 24,2 & 3,6 & 10,7 & 61,5 & 7,7 & 16,9 & 73,8 & 1,7 \\
\hline 2002 & 22,9 & 4,4 & 13,0 & 59,8 & 8,9 & 18,1 & 71,2 & 1,8 \\
\hline 2005 & 22,1 & 5,7 & 16,2 & 56,0 & 10,2 & 19,6 & 68,2 & 2,1 \\
\hline 2008 & 19,8 & 8,6 & 26,0 & 45,6 & 11,2 & 20,9 & 65,5 & 2,43 \\
\hline 2011 & 19,0 & 10,9 & 29,4 & 40,7 & 12,1 & 22,7 & 62,9 & 2,4 \\
\hline 2014 & 19,7 & 12,4 & 29,7 & 38,2 & 14,7 & 23,7 & 58,9 & 2,7 \\
\hline 2015 & 19,6 & 12,5 & 30,5 & 37,4 & 15,1 & 23,7 & 58,4 & 2,9 \\
\hline
\end{tabular}

Fonte: Elaboração própria, a partir dos microdados da PNAD, 1993-2015.

Em termos do tamanho médio das famílias, a queda do número de membros em cada família é notável (Tabela 2), refletindo o processo de transição demográfica e mudança das famílias no Brasil. Essa redução no tamanho médio das famílias brasileiras carrega os efeitos do aumento do número de homens morando sozinhos e do aumento do número de famílias de casais sem filhos (Tabela 3), este último decorrente da postergação da primeira gravidez e da própria redução da taxa de fecundidade no país. A Tabela 3 consolida a perspectiva de prevalência das famílias monoparentais entre aquelas famílias de responsabilidade feminina e a predominância das famílias de casal com filhos entre as famílias de responsabilidade masculina no Brasil urbano ao longo dos anos.

A Figura 1 apresenta a composição do mercado de trabalho. Uma das consequências da crise econômica que o Brasil enfrentou a partir de 2014 foi o aumento do desemprego e da inatividade. Dado que ambas as taxas são calculadas para os indivíduos entre 18 e 65 anos, é provável que haja dentro dessa taxa de inatividade uma parcela de indivíduos desencorajados. A maior dificuldade de encontrar emprego em certos períodos tem o potencial de gerar um efeito de desalento entre os indivíduos, que ficam desencorajados de buscar emprego e, por conseguinte, desestimulados de participar da força de trabalho como desempregados. Essa fração da po- 
pulação é relevante para análises sobre a polarização do trabalho entre as famílias, uma vez que as taxas de não trabalho individuais e domiciliares, essenciais para o cômputo da polarização, englobam a população de adultos em idade ativa desempregada e inativa. As taxas de não trabalho são fundamentais por revelarem mais faces do mercado de trabalho, na medida em que englobam também as pessoas que não estão entre os desempregados simplesmente porque desistiram de buscar trabalho.

Figura 1 Taxas de desemprego e inatividade individuais (taxa de não emprego individual), Brasil urbano, 1993-2015 (\%)

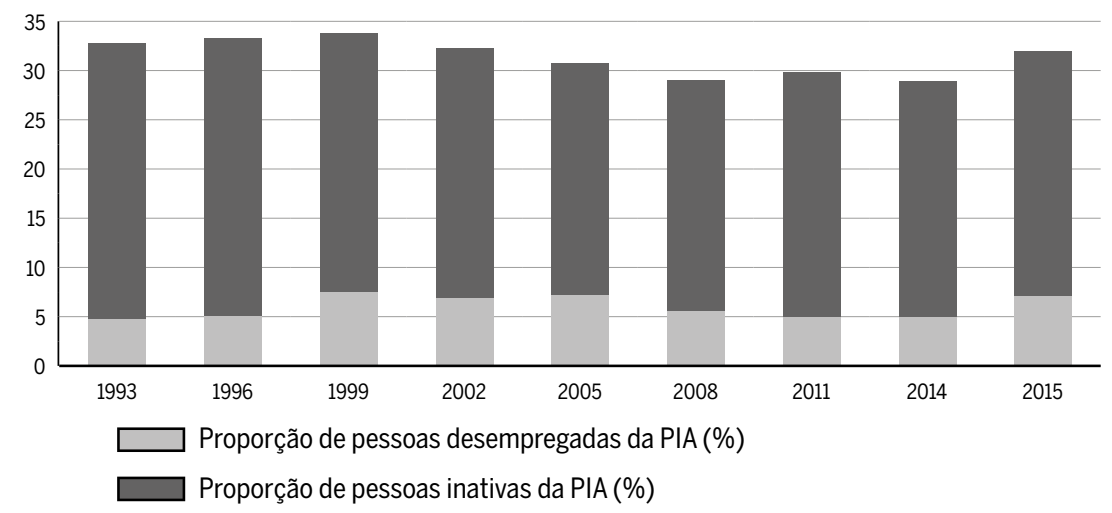

Fonte: Elaboração própria, a partir dos microdados da PNAD, 1993-2015.

\subsection{Tendências na distribuição do emprego individual entre as famílias}

O ponto fundamental desta seção é compreender se a distribuição de postos de trabalho se torna mais igualitária entre as famílias ao longo do tempo e quais os fatores associados à polarização do trabalho familiar. A Figura 2 apresenta a evolução das proporções de famílias sem trabalho e de famílias com todos os adultos ocupados. Ao longo do período, a taxa de famílias sem trabalho aumentou de 7,5\% em 1993 para $11 \%$ em 2015. Essa taxa de não trabalho familiar aparentemente é baixa, comparativamente ao padrão de outros países ocidentais, ${ }^{5}$ mas seus aumentos 5 Gregg et al. (2010) observam taxa de domicílios sem trabalho em 2005 de 16,3\% para a Grã-Bretanha, 10,8\% para a Espanha, 12,2\% para os Estados Unidos, 16,5\% para a Alema- 
sucessivos a partir de 2008 são significativos no vasto leque de problemas sociais do país.

A mudança na taxa de não trabalho familiar no período e no processo de polarização da oferta de trabalho familiar pode ser atribuída, em grande parte, às variações na organização econômica das famílias de casais, em termos dos padrões de trabalho em domicílios de casais com e sem filhos, que representam em média cerca de $70 \%$ de todos os tipos de famílias do Brasil urbano.

Figura 2 Proporção de famílias por status ocupacional dos adultos, Brasil urbano,

\section{3-2015 (\%)}

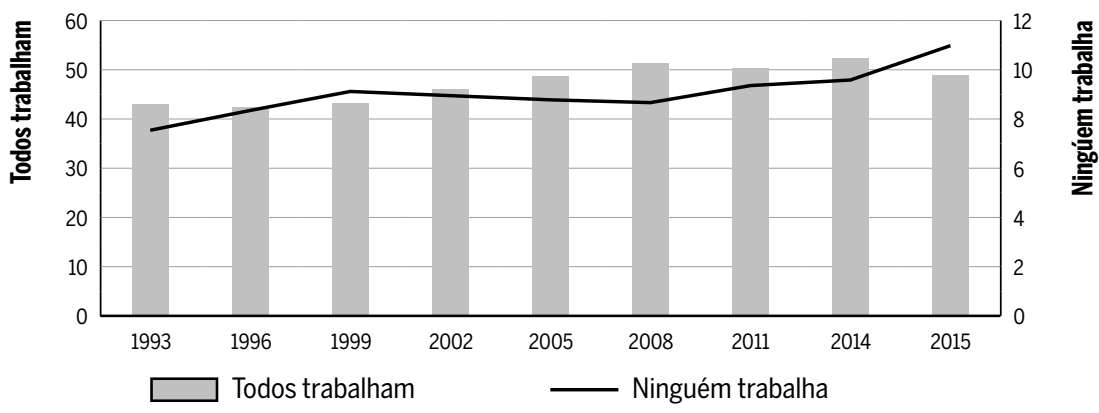

Fonte: Elaboração própria, a partir dos microdados da PNAD, 1993-2015.

Aprofundando a análise da hipótese de o aumento da taxa de não trabalho familiar no Brasil ter origem em mudanças nas estruturas familiares, a Tabela 4 mostra as participações relativas de cada tipo de família (por número de adultos com idade entre 18 e 65 anos) entre todas as famílias com adultos em idade ativa ao longo do período e entre as famílias sem trabalho. Houve mudanças no padrão de composição das famílias, com um aumento na proporção de famílias contendo apenas um adulto e declínio correspondente na proporção das famílias com dois adultos. ${ }^{6}$

nha e 14,9\% para a Austrália. A literatura destaca a existência de elevadas taxas de domicílios sem trabalho em países com menores taxas de desemprego individual e, por outro lado, taxas de domicílios sem trabalho comparativamente menores em países com maiores taxas de desemprego. A alta prevalência de famílias sem emprego não é uma consequência direta das altas taxas de não trabalho individual (OECD, 1998).

6 Desagregando os tipos de famílias para diferenciar a presença de crianças nas famílias de um adulto, verifica-se que as famílias de adultos solteiros sem filhos são responsáveis por em média $68 \%$ das famílias de um adulto e esse grupo também é responsável por maior parte do aumento no número de famílias de um adulto. 
Tabela 4 Distribuição das famílias totais e famílias sem trabalho por número de adultos, Brasil urbano, 1993-2015 (\%)

\begin{tabular}{l|r|r|r|r|r|r|r|r}
\hline Ano & \multicolumn{4}{r}{} & \multicolumn{3}{r}{$\begin{array}{r}\text { Total de famílias - } \\
\text { Número de adultos }\end{array}$} & \multicolumn{4}{|r}{$\begin{array}{r}\text { Famílias sem trabalho - } \\
\text { Número de adultos }\end{array}$} \\
\cline { 2 - 11 } & $\mathbf{1}$ & $\mathbf{2}$ & $\begin{array}{r}\text { Mais } \\
\text { de 3 }\end{array}$ & Total & $\mathbf{1}$ & $\mathbf{2}$ & $\begin{array}{r}\text { Mais } \\
\text { de 3 }\end{array}$ & Total \\
\hline $\mathbf{1 9 9 3}$ & 17,6 & 62,7 & 19,6 & 100 & 49,2 & 42,1 & 8,7 & 100 \\
\hline $\mathbf{1 9 9 6}$ & 18,2 & 60,8 & 21,0 & 100 & 50,6 & 40,8 & 8,5 & 100 \\
\hline $\mathbf{1 9 9 9}$ & 19,4 & 59,0 & 21,6 & 100 & 49,3 & 40,6 & 10,1 & 100 \\
\hline $\mathbf{2 0 0 2}$ & 20,4 & 58,0 & 21,6 & 100 & 52,9 & 38,1 & 9,0 & 100 \\
\hline $\mathbf{2 0 0 5}$ & 21,7 & 57,0 & 21,4 & 100 & 54,9 & 37,8 & 7,3 & 100 \\
\hline $\mathbf{2 0 0 8}$ & 22,8 & 55,5 & 21,6 & 100 & 57,7 & 35,6 & 6,8 & 100 \\
\hline $\mathbf{2 0 1 1}$ & 23,5 & 55,7 & 20,8 & 100 & 58,3 & 35,8 & 6,0 & 100 \\
\hline $\mathbf{2 0 1 4}$ & 25,4 & 54,6 & 20,0 & 100 & 60,6 & 33,7 & 5,7 & 100 \\
\hline $\mathbf{2 0 1 5}$ & 25,6 & 54,3 & 20,1 & 100 & 57,6 & 35,9 & 6,4 & 100 \\
\hline
\end{tabular}

Fonte: Elaboração própria, a partir dos microdados da PNAD, 1993-2015.

As mudanças no tamanho das famílias, em termos de adultos residentes, refletem sobre a composição das famílias sem trabalho. Como resultado da mudança para a prevalência de estruturas familiares menores, as famílias de um adulto constituem $57,6 \%$ de todas as famílias sem emprego em 2015. Espera-se que quanto maior o número de adultos na família, menor seja a chance de nenhum deles estar trabalhando.

Em toda a análise da medida de polarização do trabalho familiar, os diferentes tipos de famílias são referentes exclusivamente ao número de adultos (Figura 3). A polarização negativa no Brasil foi verificada anteriormente por Scorzafave e Menezes-Filho (2007), para o período de $1981(-8 \%)$ a $2003(-5 \%)$, tendo sido essa polarização crescente até 2001, a partir de quando esse crescimento se estaciona. $O$ questionamento que emerge sobre o que ocorre a partir de 2003 com a medida de polarização brasileira é respondido pela visualização da Figura 3, que mostra o subsequente crescimento dessa taxa. Destaca-se a acelerada velocidade em que a taxa de famílias sem trabalho observada se aproxima da taxa de famílias sem trabalho contrafactual entre 1999 e 2008. Nesse período ocorre au-

7 Resultados com tendências similares são constatados para a Austrália no intervalo 19821998 por Dawkins et al. (2002) e para o Brasil no intervalo 1981-2003 por Scorzafave e Menezes-Filho (2007). 
mento na proporção de famílias em que todos os adultos estão ocupados concomitantemente a uma redução na proporção de famílias sem algum adulto empregado (Figura 2). Esse cenário pode ser compreendido à luz da tendência de maior inserção feminina na força de trabalho .

\section{Figura 3 Evolução da polarização da oferta de trabalho familiar, Brasil urbano, 1993-}

\section{$2015(\%)$}

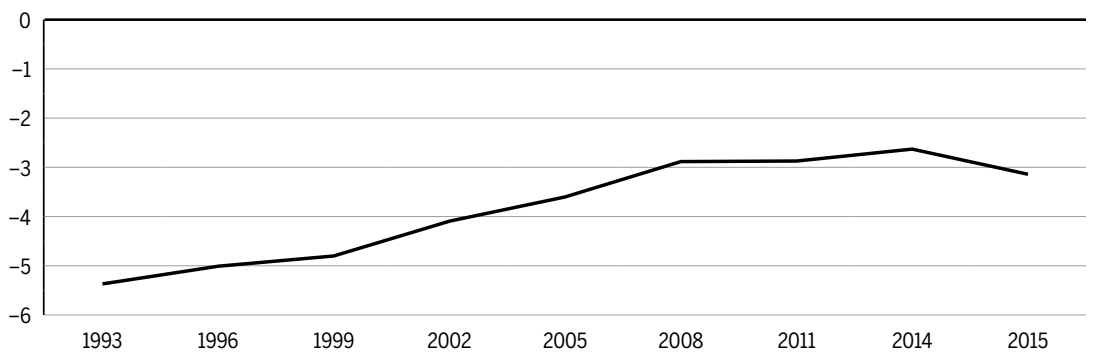

Fonte: Elaboração própria, a partir dos microdados da PNAD, 1993-2015.

Segundo Gregg et al. (2010), uma polarização negativa do trabalho seria consistente com as teorias de gênero sobre a divisão do tempo de não trabalho e de trabalho, que se assentam em um processo de especialização das atividades de trabalho familiar. Contudo, tais teorias, desenvolvidas em um contexto empírico de prevalência da organização econômica tradicional das famílias, de predomínio de famílias de provedor homem, não são mais suficientes para explicar toda a complexidade da oferta de trabalho familiar. A predominância das famílias de único provedor masculino em uma sociedade garante que haja muitas famílias de dois adultos nas quais pelo menos um adulto (supostamente o homem) trabalha e relativamente poucas famílias de dois adultos que estejam sem trabalho. Entretanto, também o contingente de famílias de duplo provedor (com todos os adultos empregados) será pequeno, o que é negativo em termos de bem-estar social.

Por outro lado, a teoria do efeito trabalhador adicional sugere que a presença (ausência) de um adulto ocupado em uma família reduziria (au8 Hermeto e Rios-Neto (2004) constataram que a taxa de participação feminina na força de trabalho brasileira se elevou substancialmente para todas as idades de 1981 a 1999, sendo que as distintas experiências educacionais das coortes parecem ser um importante determinante da variação da participação na força de trabalho. Com algumas oscilações, as taxas de atividade feminina continuam a aumentar após 1999 (Alves; Cavenaghi, 2012). 
mentaria) a oferta de trabalho de outros residentes (Spletzer, 1997; Cullen; Gruber, 2000; Bredtmann et al., 2014). Em termos da polarização do trabalho, a teoria do trabalhador adicional significa um número mais elevado de ocupados entre as famílias de adultos solteiros (unipessoais e algumas famílias monoparentais), mas também menos famílias totalmente ocupadas, o que também é consistente com uma medida negativa de polarização.

A situação brasileira se assemelha à observada por Gregg et al. (2010) para Espanha e Alemanha, que, apesar do crescimento da polarização, foram ainda em 2005 os únicos países com polarização negativa, entre os países analisados. A diferença desses países em relação ao Brasil é que os índices se aproximam de zero nos anos mais recentes, indicativo de que as taxas de não trabalho individuais e familiares estão ficando mais alinhadas, fato ainda não percebido para os resultados brasileiros. O cenário geral é de uma taxa de famílias sem trabalho observada crescendo de 7,5\% para $11 \%$ e uma taxa de não trabalho individual brasileira caindo de $38,6 \%$ para $31,7 \%$ no período analisado. Simultaneamente, a proporção de famílias com apenas um adulto aumentou de $17,6 \%$ para 25,6\% (Tabela 4).

Faz-se necessário identificar quanto da variação da polarização do trabalho pode ser explicada pela mudança na taxa de não trabalho individual e quanto pode ser explicada pela mudança no número médio de adultos das famílias. Na primeira parte da Tabela 5, a variação na taxa de famílias sem trabalho prevista entre 1993 e 2015 é decomposta na variação devido à mudança na taxa de não trabalho individual e na variação devido à mudança na composição da família em termos de número de adultos (conforme equação 4).

A taxa de famílias sem trabalho prevista aumenta de 1993 para 2015; dado que a taxa de não trabalho individual se reduz, as taxas de famílias sem trabalho prevista e observada deveriam também se reduzir (na linha 3). Contudo as alterações na estrutura familiar exercem uma pressão ascendente sobre as taxas de não trabalho familiar ao longo do tempo (linha 2). A variação na taxa de famílias sem trabalho observada é a soma das linhas 1 e 4 da Tabela 5. Portanto, comparando as linhas 2 e 4, nota-se que a contribuição da polarização para a mudança na taxa de famílias sem trabalho é maior do que o componente de estrutura familiar no Brasil. Isso significa que as divergências entre as medidas de não trabalho familiares e individuais decorrem mais de uma crescente distribuição distorcida do emprego entre as famílias do que de mudanças na estrutura familiar. 
Tabela 5 Variação e decomposição da medida de polarização e da taxa de não trabalho familiar, Brasil urbano, 1993-2015

\begin{tabular}{lr}
\hline Variação na taxa de famílias sem trabalho contrafactual & $\mathbf{1 , 2 0 4 3}$ \\
\hline Impacto devido à mudança da composição familiar & 1,7811 \\
\hline Impacto devido à mudança na taxa de não trabalho & $-0,5768$ \\
\hline Variação na polarização & $\mathbf{2 , 2 2 6 5}$ \\
\hline Decomposição entre tipos de famílias & $-1,7802$ \\
\hline Decomposição dentro dos tipos de famílias & 4,0066 \\
\hline
\end{tabular}

Fonte: Elaboração própria, com os dados da PNAD de 1993 a 2015.

A decomposição da variação da polarização observada no país entre 1993 e 2015 vista na Tabela 5 aponta que a maior parte da polarização ocorre dentro dos tipos de famílias (linha 6) - isto é, dentro do grupo de todas as famílias de um adulto, dentro do grupo de todas as famílias de dois adultos, e assim sucessivamente -, e não por causa do aumento na proporção de tipos de famílias que já apresentam alta polarização. Desse modo, o componente entre tipos de famílias da polarização na linha 5 é inferior ao componente das mudanças dentro dos tipos de famílias na linha 6 . A composição de adultos das famílias (linha 2) contribui menos do que a polarização dentro dos tipos de família (linha 6) para o crescimento da taxa de não trabalho familiar observada. Esse tipo de resultado é frequente em outros países, nos quais as explicações para as divergências entre as medidas de não trabalho familiares e individuais estão mais interligadas às condições do mercado de trabalho e às interações de cada tipo de família com o mercado de trabalho (GREGG et al., 2010). Nesse contexto, é fundamental compreender melhor os fatores de risco associados à probabilidade de estar em famílias sem trabalho no Brasil.

\subsection{Estimações dos riscos de viver em uma família sem trabalho}

Com o intuito de compreender o contexto familiar da desocupação e inatividade, são estimados modelos de regressão logit multinomial que predizem a probabilidade de indivíduos adultos estarem em uma família sem trabalho e a probabilidade de estar em uma família em que todos trabalham, vis-à-vis estar numa família em que pelo menos uma pessoa trabalha. $O$ modelo inclui variáveis individuais, familiares e regionais. As esti- 
mações são conduzidas para os anos de 1993, 2005, 2015 e para o intervalo 1993-2015, para homens e mulheres separadamente. A escolha da categoria de referência da variável dependente do modelo é realizada considerando a abordagem da existência de "melhores famílias" para se viver (Gregg; Wadsworth, 1996; Lehmann; Wadsworth, 1997; Nolen, 2013). As tabelas com os resultados completos das estimações se encontram no Apêndice.

A Tabela 6 resume as razões de riscos relativos para homens e mulheres das variáveis que traduzem as características demográficas individuais e dos arranjos familiares nos períodos inicial e final. Homens e mulheres com mais elevada qualificação educacional são menos propensos a viver em famílias sem trabalho e, especialmente, aqueles com mais de 15 anos de estudo possuem elevadas chances de estar numa família em que todos os adultos trabalham comparativamente àqueles em que nem todos os adultos trabalham. Tais efeitos do nível educacional não mudaram significativamente ao longo dos anos. Os riscos de estar em famílias sem trabalho se reduzem com a idade, sinalizando um efeito geracional. Por exemplo, um indivíduo que tinha entre 60 e 62 anos de idade em 1993 apresentava maior risco de estar numa família sem trabalho do que um indivíduo no mesmo grupo etário em 2015.

O tamanho da família apresenta uma relação inversa com o risco individual de viver em uma família sem trabalho. É esperado que quanto maior o tamanho da família mais provável seja ter pelo menos um adulto trabalhando. O papel desempenhado pelas redes familiares - de apoio à renda, de compartilhamento das atividades domésticas e de cuidado dos filhos e/ou idosos, e para estabelecer contatos sociais de trabalho - é essencial.

Estar em famílias com elevadas razões de dependência de crianças e de idosos apresentam riscos mais altos de estar em famílias sem trabalhos; tais riscos aumentam em 2015 para a razão de dependência de idosos. As mulheres que vivem com crianças e apresentam elevada razão de dependência têm maior probabilidade de estar em famílias sem trabalho, e tais chances são mais expressivas do que as dos homens. Os significativos e crescentes riscos individuais de ocorrência de não trabalho em famílias com altas razões de dependência de crianças revelam um cenário preocupante para o Brasil, em termos dos desafios futuros que essas crianças, provenientes de famílias sem trabalho, irão enfrentar. Uma recorrente consequência de viver em uma família sem trabalho é o risco da transmissão da falta de trabalho e da pobreza intergeracional (NESC, 2014). Em termos 
da maior razão de dependência familiar dos idosos, comparativamente ao número de crianças dependentes, o idoso, além de requisitar cuidados, é um potencial gerador de renda para as famílias, através da renda de aposentadoria. Dessa forma as famílias com idosos frequentemente têm certo nível de renda familiar assegurado, o que torna mais provável a possibilidade de que nenhum dos adultos esteja recebendo renda do trabalho.

Tabela 6 Resumo das razões de riscos relativos de estar numa família sem trabalho para adultos no Brasil urbano, 1993 e 2015

\begin{tabular}{|c|c|c|c|c|c|c|c|c|}
\hline \multirow[t]{3}{*}{ Ano } & \multicolumn{4}{|r|}{ Homens } & \multicolumn{4}{|r|}{ Mulheres } \\
\hline & \multicolumn{2}{|r|}{1993} & \multicolumn{2}{|r|}{2015} & \multicolumn{2}{|r|}{1993} & \multicolumn{2}{|r|}{2015} \\
\hline & $\begin{array}{r}\text { Sem } \\
\text { trabalho }\end{array}$ & $\begin{array}{c}\text { Todos } \\
\text { traba- } \\
\text { lham }\end{array}$ & $\begin{array}{r}\text { Sem } \\
\text { trabalho }\end{array}$ & $\begin{array}{r}\text { Todos } \\
\text { traba- } \\
\text { Iham }\end{array}$ & $\begin{array}{r}\text { Sem } \\
\text { trabalho }\end{array}$ & $\begin{array}{r}\text { Todos } \\
\text { traba- } \\
\text { lham }\end{array}$ & $\begin{array}{r}\text { Sem } \\
\text { trabalho }\end{array}$ & $\begin{array}{r}\text { Todos } \\
\text { traba- } \\
\text { lham }\end{array}$ \\
\hline \multicolumn{9}{|c|}{ Faixa etária (18-20 omitida) } \\
\hline $27-29$ & $0,44 * * *$ & $0,78^{* * *}$ & $0,61^{* * *}$ & $1,23^{* * *}$ & 0,61 *** & $1,45^{* * *}$ & $0,71^{* * *}$ & $1,71^{* * *}$ \\
\hline $36-38$ & $0,61^{* * *}$ & 1,07 & $0,54^{* * *}$ & $1,66^{* * *}$ & 1,04 & $2,68^{* * *}$ & 1,10 & $2,86^{* * *}$ \\
\hline $45-47$ & 0,96 & $1,15^{* *}$ & $0,67^{* * *}$ & $1,63^{* * *}$ & $1,44^{* * *}$ & $1,87^{* * *}$ & 0,93 & $2,12^{* * *}$ \\
\hline $54-56$ & $1,96^{* * *}$ & $0,66^{* * *}$ & 0,91 & 1,07 & $2,22^{* * *}$ & 1,09 & $1,50^{* * *}$ & $1,31^{* * *}$ \\
\hline $60-62$ & $3,06^{* * *}$ & $0,47^{* * *}$ & $1,58^{* * *}$ & $0,67^{* * *}$ & $2,78^{* * *}$ & $0,75^{* * *}$ & $2,33^{* * *}$ & $0,86^{* * *}$ \\
\hline \multicolumn{9}{|c|}{ Anos de estudo (até 3 anos omitida) } \\
\hline 11 a 14 & $0,68^{* * *}$ & 0,99 & $0,51^{* * *}$ & $1,33^{* * *}$ & $0,68^{* * *}$ & $1,58^{* * *}$ & $0,52^{* * *}$ & $1,67^{* * *}$ \\
\hline 15 ou mais & $0,55^{* * *}$ & $1,38^{* * *}$ & $0,42^{* * *}$ & $1,63^{* * *}$ & $0,59 * * *$ & $2,59 * * *$ & $0,37^{* * *}$ & $2,34^{* * *}$ \\
\hline Tamanho da família & $0,56^{* * *}$ & $0,69 * * *$ & $0,43^{* * *}$ & $0,49 * * *$ & $0,52^{* * *}$ & $0,69 * * *$ & $0,39 * * *$ & $0,50^{* * *}$ \\
\hline \multicolumn{9}{|c|}{ Razão de dependência familiar } \\
\hline Crianças & $2,14^{* * *}$ & $1,72^{* * *}$ & $3,24 * * *$ & $2,80^{* * *}$ & $3,21^{* * *}$ & $2,13 * * *$ & $5,27^{* * *}$ & $3,18^{* * *}$ \\
\hline Idosos & $5,59 * * *$ & $2,27^{* * *}$ & $5,80^{* * *}$ & $2,14^{* * *}$ & $6,49 * * *$ & $1,99 * * *$ & $6,98^{* * *}$ & $2,05^{* * *}$ \\
\hline $\begin{array}{l}\text { Família com } \\
\text { responsável mulher }\end{array}$ & $2,15^{* * *}$ & 0,99 & $1,09 * *$ & $0,88^{* * *}$ & $2,74^{* * *}$ & $2,03^{* * *}$ & $1,73^{* *}$ & $1,20 * * *$ \\
\hline
\end{tabular}

Fonte: Elaboração própria, a partir dos microdados da PNAD, 1993-2015.

Nota: Desvios padrão entre parêntesis. Níveis de significância: ***1\%, **5\%, ${ }^{*} 10 \%$.

Diferentemente dos homens, as mulheres em famílias de responsabilidade feminina apresentam maiores chances de estar numa família em que todos os adultos trabalham do que aquelas em famílias de responsabilidade masculina, vis-à-vis estarem numa família em que nem todos os adultos trabalham. A autodeclaração de uma família como de responsabilidade feminina 
é per se uma ruptura nos padrões tradicionais de organização econômica das famílias (de único provedor homem), o que justificaria essa constatação.

Em síntese, homens e mulheres são mais propensos a viver em famílias sem emprego em idades mais avançadas. O nível de escolaridade mais elevado parece diminuir o risco de estar em uma família sem emprego tanto para homens quanto para mulheres. $O$ fato de homens e mulheres com maior escolaridade apresentarem menores probabilidades de estar em famílias sem emprego, em comparação com os sem escolaridade e com menos de três anos de estudo, pode ser explicado pela ocorrência de que tais adultos também têm certamente menor probabilidade de estar desempregados, uma vez que níveis mais elevados de escolaridade conduzem a menores riscos de desemprego. Outra possibilidade é que, no caso de famílias em que há corresidência com um parceiro, os status ocupacionais dos cônjuges estejam fortemente associados, o que é resultante da maior homogamia educacional e da seletividade marital. $O$ crescimento da homogamia educacional, entre as famílias de casais, é um resultado observado no Brasil urbano no período analisado. Os resultados indicam que os arranjos familiares são importantes para explicar o maior risco relativo de estar numa família sem trabalho.

\section{Comentários conclusivos}

O crescimento do número de famílias sem trabalho deve ser uma das principais preocupações de um país, uma vez que o resultado desse indicador pode antecipar um cenário de maior desigualdade de renda e piora no bem-estar de uma sociedade. Objetivando obter uma compreensão aprofundada das inter-relações entre mercado de trabalho nacional e a evolução na composição das famílias, este artigo investigou a polarização da oferta de trabalho familiar no Brasil urbano entre 1993 e 2015. Com os dados da PNAD, foi possível acompanhar a evolução anual das taxas de famílias sem emprego observada e contrafactual e, na sequência, estimar por meio de um modelo logit multinomial os fatores de risco individual de viver em uma família sem trabalho e em uma família em que todos os adultos estão empregados.

Para a análise da polarização da oferta de trabalho familiar no Brasil urbano, apesar de ser constatada uma taxa de famílias sem trabalho que 
varia relativamente pouco ao longo dos anos, observa-se uma polarização crescente e um aumento na taxa de famílias sem trabalho. A predominância das famílias de único provedor masculino no Brasil até os anos 1990 garantia a existência de muitas famílias de dois adultos em que pelo menos um adulto trabalhava, e relativamente poucas sem trabalho. Por outro lado, dada essa predominância da organização econômica tradicional das famílias, o contingente de famílias de duplo provedor foi relativamente pequeno durante um longo período, levando a uma medida de polarização negativa. Tal cenário pode ser prejudicial em termos de bem-estar social e, sobretudo, dada a dificuldade que seria para uma família de único provedor, que transita primeiro para situação de não trabalho familiar, mover-se novamente para condição de único provedor. Adicionalmente, no Brasil as divergências entre as medidas de não trabalho domiciliares e individuais decorrem mais de uma crescente distribuição distorcida do emprego entre as famílias do que de mudanças na estrutura familiar.

Os resultados indicam que a maior parte da variação na polarização de 1993 para 2015 ocorre dentro das tipologias de famílias por número de adultos, e não devido ao aumento na proporção de tipos de famílias que já sofrem alta polarização. A composição das famílias em termos de número de adultos contribui menos do que a polarização dentro dos tipos de família para o crescimento da taxa de não trabalho familiar observada.

As discrepâncias entre as medidas de não trabalho familiares e individuais estão atreladas, portanto, a fatores internos às famílias e a mudanças no mercado de trabalho. As desigualdades perpetuadas pelos padrões de união conjugal, decorrentes da seletividade marital e da homogamia educacional, aumentam a concentração do desemprego e inatividade em algumas famílias. Esse aspecto é especialmente relevante no Brasil por se tratar de uma modificação que ocorre dentro dos tipos de família e, portanto, contribui mais para o crescimento da taxa de não trabalho familiar observada.

O risco individual de estar numa família sem trabalho está relacionado com características individuais e da estrutura familiar. Indivíduos adultos com mais qualificações educacionais são menos propensos a viver em famílias sem trabalho. $O$ tamanho da família apresenta uma relação inversa com o risco individual de viver em uma família sem trabalho. Portanto, quanto maior o tamanho da família mais provável é que haja pelo menos um adulto trabalhando. Todavia, as mulheres que vivem com mais crian- 
ças (possuem elevada razão de dependência infantil) têm maior probabilidade de estar em famílias sem trabalho, e tais chances são mais expressivas do que aquelas observadas para os homens.

A interpretação para o efeito da presença de crianças na família é ambígua. Por um lado, a presença de filhos está interligada à necessidade de um nível mínimo de rendimento, que garanta o sustento familiar, de modo que adultos em famílias "maiores" (em termos de residentes) têm menos chances de estar numa família sem trabalho. Por outro lado, quanto maior o número de crianças, maior é o tempo familiar dedicado a cuidado - especialmente para as mulheres -, o que eleva os riscos de estar numa família sem trabalho.

A composição das famílias parece ser determinante para a complexidade dos arranjos familiares sem trabalho. Assim, frente à diversidade brasileira das estruturas familiares sem trabalho, faz-se necessário pensar ações que reflitam essa complexidade e necessidades dessas famílias, em termos de propostas para que seus membros regressem ou entrem no mercado de trabalho. Nesse sentido, um requisito básico é a disponibilização de serviços de cuidados infantis acessíveis e de qualidade, sobretudo para atender às necessidades das famílias monoparentais e de casais com filhos.

Especialmente no contexto brasileiro de mudanças demográficas, marcado por profundas modificações das estruturas familiares, em termos de escolaridade média, número de crianças, tamanho das famílias e número de adultos, abordar as questões que esses agregados familiares sem trabalho enfrentam é fundamental. Tais análises fomentam, por exemplo, o debate sobre desemprego entre os jovens e entre as famílias unipessoais, o que é essencial para se traçar tendências futuras sobre as características e a composição da força de trabalho.

\section{Referências}

ALVES, J. E. D.; CAVENAGHI, S. M. Indicadores de desigualdade de gênero no Brasil. Mediações, v. 17, n. 2, p. 83-105, 2012.

BILAC, E. D. Trabalho e família: Articulações possíveis. Tempo Social, v. 26, n. 1, p. 129-145, 2014.

BREDTMANN, J.; OTTEN, S.; RULFF, C. Husband's unemployment and wife's labor supply - the added worker effect across Europe. Germany: Ruhr-Department of Economics at Universität Bochum (RUB), 2014. 49 p. (Economic Paper, 484) 
CORLUY, V.; VANDENBROUCKE, F. Individual employment, household employment and risk of poverty in the EU: A decomposition analysis. Luxembourg: Publications Office of the European Union, 2013.

CULLEN, J.; GRUBER, J. Does unemployment crowd out spousal labor supply? Journal of Labor Economics, v. 18, n. 3, p. 546-572, 2000.

DANZIGER, L.; KATZ, E. A theory of sex discrimination. Journal of Economic Behavior and Organization, v. 31, n. 1, p. 57-66, 1996.

DAWKINS, P.; GREGG, P.; SCUTELLA, R. Employment polarisation in Australia. United Kingdom: The Centre for Market and Public Organisation-Department of Economics at University of Bristol, 2002. 53 p. (CMPO Working Paper, 02/50)

FRANÇOIS, P. A theory of gender discrimination based on the household. Journal of Public Economics, v. 68, n. 1, p. 1-32, 1998.

GREGG, P.; JERRIM, J.; MACMILLAN, L.; SHURE, N. Children in jobless households across Europe: Evidence on the association with medium- and long-term outcomes. London: UCL Institute of Education, University College London, 2017. (Working Paper, 17-05).

GREGG, P.; SCUTELLA, R.; WADSWORTH, J. Reconciling workless measures at the individual and household level. Theory and evidence from the United States, Britain, Germany, Spain and Australia. Journal of Population Economics, v. 23, p. 139-167, 2010.

GREGG P.; WADSWORTH, J. More work in fewer households? In: HILLS, J. (Org.). New Inequalities. London: Cambridge University Press, 1996. p. 181-207.

GREGG P.; WADSWORTH, J. It Takes Two: Employment Polarisation in the OECD. London: Centre for Economic Performance, 1998. (Discussion Paper, 304).

GREGG, P.; WADSWORTH, J. Why we should (also) measure worklessness at the household level: Theory and evidence from Britain, Spain, Germany and the United States. London: Centre for Economic, London School of Economics, 2002. (Working Paper, 1.168).

GREGG, P.; WADSWORTH, J. Everything you ever wanted to know about measuring worklessness and polarization at the household level but were afraid to ask. Oxford Bulletin of Economics and Statistics, v. 63, special issue, p. 777-806, 2001.

GREGG, P.; WADSWORTH, J. Two sides to every story: measuring polarization and inequality in the distribution of work. Journal of the Royal Statistical Society, v. 171, n. 4, p. 857-875, 2008.

HERMETO, A. M.; RIOS-NETO, E. L. G. Modelos idade-período-coorte aplicados à participação na força de trabalho: em busca de uma versão parcimoniosa. Revista Brasileira de Estudos Populacionais, v. 21, n. 1, p. 21-47, 2004.

KÖKSEL, P. Living arrangements of the unemployed across Europe: How households protect us from vulnerability. Thesis (Doctor of Demography) - Universitat Autónoma de Barcelona, Centre D'Estudis Demografics, Barcelona, 2017.

KÖKSEL, P.; PERMANYER, I; ESTEVE, A. How do living arrangements affect the prevalence of jobless households across European regions? In: European Population Conference (EPC 2016), 2016, Mainz, Germany, 31 ${ }^{\text {st }}$ August to $3^{\text {rd }}$ September, 2016.

LEHMANN, H.; WADSWORTH, J. New jobs, worklessness and households in Poland. European Economic Review, v. 41, p. 915-923, 1997. 
NOLEN, P. Unemployment and household values: Distribution sensitive measures of unemployment. Labour Economics, v. 24, p. 354-362, 2013.

NESC. Jobless Households: An Exploration of the Issues. Dublin: National Economic and Social Council, 2014. N. 137. 49 p.

OECD. OECD Employment Outlook, Paris: OECD Publishing, 1998. 216 p.

RUGGLES, S. Patriarchy, power, and pay: The transformation of American families, 18002015. Demography, v. 52, p. 1.797-1.823, 2015.

SCORZAFAVE, L. G.; MENEZES-FILHO, N. A. Famílias com trabalho e famílias sem trabalho: evidências de polarização para o Brasil. Estudos Econômicos, v. 37, n. 3, p. 563-584, 2007.

SINGLEY, S. G.; CALLISTER, P. Work poor or working poor? A comparative perspective on New Zealand's jobless households. Economic Inquiry, v. 20, p. 134-155, 2003.

SPLETZER, J. Reexamining the added worker effect. Economic Inquiry, v. 35, n. 2, p. 417-427, 1997.

VIEIRA, C. S.; MENEZES-FILHO, N.; KOMATSU, B. K. Como as mudanças no trabalho e renda dos pais afetam as escolhas entre estudo e trabalho dos jovens? Pesquisa e Planejamento Econômico, v. 46, n. 3, p. 33-61, 2016.

WAJNMAN, S. Demografia das famílias e dos domicílios brasileiros. Tese (Professor Titular em Demografia) - Universidade Federal de Minas Gerais, Cedeplar, Belo Horizonte, 2012.

\section{Sobre os autores}

Danyella Juliana Martins de Brito - danyella.brito@ufpe.br

Programa de Pós-graduação em Economia, Universidade Federal de Pernambuco, Caruaru, PE, Brasil. ORCID: https://orcid.org/0000-0002-9630-2577.

Ana Maria Hermeto Camilo de Oliveira-ahermeto@cedeplar.ufmg.br

Centro de Desenvolvimento e Planejamento Regional, Universidade Federal de Minas Gerais, Belo Horizonte, MG, Brasil. ORCID: https://orcid.org/0000-0001-8331-1928.

\section{Sobre o artigo}

Recebido em 20 de setembro de 2019. Aprovado em 16 de novembro de 2020. 


\section{APÊNDICE A}

Razões de riscos relativos de estar numa família sem trabalho para adultos no Brasil urbano, 1993-2015, estimadas pelos modelos Logit multinomiais.

Tabela A1 Homens, 1993, 2005 e 2015

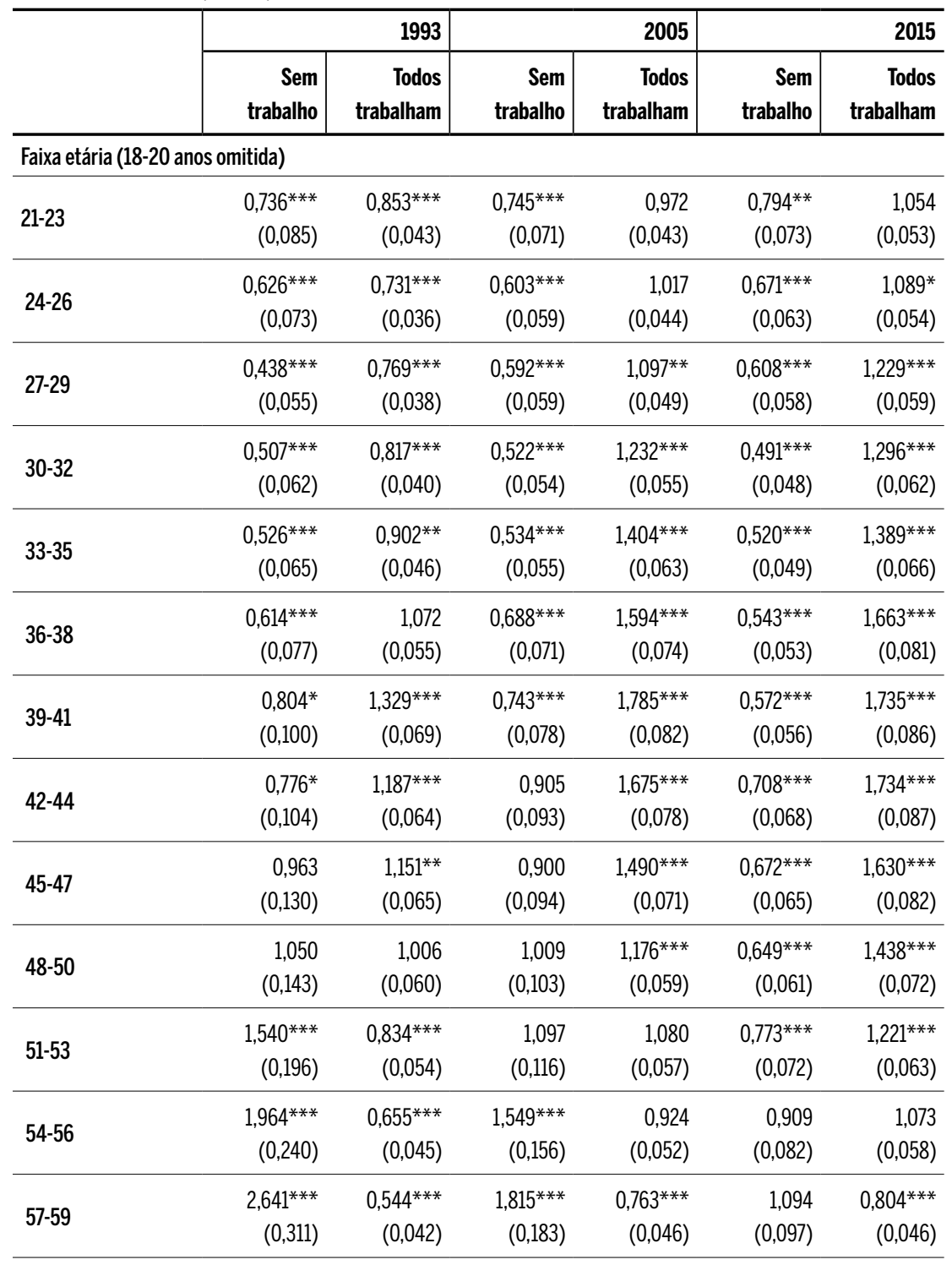

(continua) 
Tabela A1 (continuação)

\begin{tabular}{|c|c|c|c|c|c|c|}
\hline & \multicolumn{2}{|r|}{1993} & \multicolumn{2}{|r|}{2005} & \multicolumn{2}{|r|}{2015} \\
\hline & $\begin{array}{r}\text { Sem } \\
\text { trabalho }\end{array}$ & $\begin{array}{r}\text { Todos } \\
\text { trabalham }\end{array}$ & $\begin{array}{r}\text { Sem } \\
\text { trabalho }\end{array}$ & $\begin{array}{r}\text { Todos } \\
\text { trabalham }\end{array}$ & $\begin{array}{r}\text { Sem } \\
\text { trabalho }\end{array}$ & $\begin{array}{r}\text { Todos } \\
\text { trabalham }\end{array}$ \\
\hline $60-62$ & $\begin{array}{r}3,057^{* * *} \\
(0,359)\end{array}$ & $\begin{array}{r}0,468^{* * *} \\
(0,038)\end{array}$ & $\begin{array}{r}2,382^{* * *} \\
(0,237)\end{array}$ & $\begin{array}{r}0,654^{* * *} \\
(0,043)\end{array}$ & $\begin{array}{r}1,577^{* * *} \\
(0,138)\end{array}$ & $\begin{array}{r}0,674^{* * *} \\
(0,041)\end{array}$ \\
\hline $63-65$ & $\begin{array}{r}2,187^{* * *} \\
(0,279)\end{array}$ & $\begin{array}{r}0,443^{* * *} \\
(0,039)\end{array}$ & $\begin{array}{r}2,090 * * * \\
(0,220)\end{array}$ & $\begin{array}{r}0,448 * * * \\
(0,034)\end{array}$ & $\begin{array}{r}1,276^{* * *} \\
(0,118)\end{array}$ & $\begin{array}{r}0,420 * * * \\
(0,029)\end{array}$ \\
\hline \multicolumn{7}{|c|}{ Anos de estudo (até 3 anos omitida) } \\
\hline 4 a 7 & $\begin{array}{r}0,834^{* * *} \\
(0,047)\end{array}$ & $\begin{array}{r}0,891^{* * *} \\
(0,024)\end{array}$ & $\begin{array}{r}0,789 * * * \\
(0,040)\end{array}$ & $\begin{array}{r}1,031 \\
(0,029)\end{array}$ & $\begin{array}{r}0,702^{* * *} \\
(0,036)\end{array}$ & $\begin{array}{r}1,097^{* * *} \\
(0,038)\end{array}$ \\
\hline 8 a 10 & $\begin{array}{r}0,708^{* * *} \\
(0,054)\end{array}$ & $\begin{array}{r}0,882^{* * *} \\
(0,029)\end{array}$ & $\begin{array}{r}0,726^{* * *} \\
(0,044)\end{array}$ & $\begin{array}{r}1,123^{* * *} \\
(0,035)\end{array}$ & $\begin{array}{r}0,630 * * * \\
(0,036)\end{array}$ & $\begin{array}{r}1,245^{* * *} \\
(0,044)\end{array}$ \\
\hline 11 a 14 & $\begin{array}{r}0,678^{* * *} \\
(0,051)\end{array}$ & $\begin{array}{r}0,995 \\
(0,032)\end{array}$ & $\begin{array}{r}0,559 * * * \\
(0,032)\end{array}$ & $\begin{array}{r}1,230^{* * *} \\
(0,034)\end{array}$ & $\begin{array}{r}0,508^{* * *} \\
(0,027)\end{array}$ & $\begin{array}{r}1,333^{* * *} \\
(0,043)\end{array}$ \\
\hline 15 ou mais & $\begin{array}{r}0,546^{* * *} \\
(0,059)\end{array}$ & $\begin{array}{r}1,379^{* * *} \\
(0,058)\end{array}$ & $\begin{array}{r}0,395^{* * *} \\
(0,034)\end{array}$ & $\begin{array}{r}1,471^{* * *} \\
(0,053)\end{array}$ & $\begin{array}{r}0,419 * * * \\
(0,029)\end{array}$ & $\begin{array}{r}1,629 * * * \\
(0,061)\end{array}$ \\
\hline $\begin{array}{l}\text { Migrante } \\
\text { intermunicipal }\end{array}$ & $\begin{array}{l}0,897^{* *} \\
(0,042)\end{array}$ & $\begin{array}{r}1,028 \\
(0,022)\end{array}$ & $\begin{array}{l}0,938^{*} \\
(0,036)\end{array}$ & $\begin{array}{r}1,060^{* * *} \\
(0,019)\end{array}$ & $\begin{array}{r}0,957 \\
(0,033)\end{array}$ & $\begin{array}{r}1,043^{* *} \\
(0,019)\end{array}$ \\
\hline Tamanho da família & $\begin{array}{r}0,559 * * * \\
(0,012)\end{array}$ & $\begin{array}{r}0,692^{* * *} \\
(0,006)\end{array}$ & $\begin{array}{r}0,430^{* * *} \\
(0,009)\end{array}$ & $\begin{array}{r}0,568^{* * *} \\
(0,005)\end{array}$ & $\begin{array}{r}0,426^{* * *} \\
(0,009)\end{array}$ & $\begin{array}{r}0,495^{* * *} \\
(0,005)\end{array}$ \\
\hline \multicolumn{7}{|c|}{ Razão de dependência familiar } \\
\hline Crianças & $\begin{array}{r}2,140 * * * \\
(0,122)\end{array}$ & $\begin{array}{r}1,720^{* * *} \\
(0,038)\end{array}$ & $\begin{array}{r}3,069 * * * \\
(0,169)\end{array}$ & $\begin{array}{r}2,104^{* * *} \\
(0,047)\end{array}$ & $\begin{array}{r}3,239 * * * \\
(0,193)\end{array}$ & $\begin{array}{r}2,803^{* * *} \\
(0,076)\end{array}$ \\
\hline Idosos & $\begin{array}{r}5,594^{* * *} \\
(0,421)\end{array}$ & $\begin{array}{r}2,273^{* * *} \\
(0,130)\end{array}$ & $\begin{array}{r}5,591^{* * *} \\
(0,322)\end{array}$ & $\begin{array}{r}2,108^{* * *} \\
(0,096)\end{array}$ & $\begin{array}{r}5,800^{* * *} \\
(0,295)\end{array}$ & $\begin{array}{r}2,135^{* * *} \\
(0,089)\end{array}$ \\
\hline $\begin{array}{l}\text { Família com } \\
\text { responsável mulher }\end{array}$ & $\begin{array}{r}2,152^{* * *} \\
(0,155)\end{array}$ & $\begin{array}{r}0,992 \\
(0,039)\end{array}$ & $\begin{array}{r}1,532^{* * *} \\
(0,072)\end{array}$ & $\begin{array}{r}0,906^{* * *} \\
(0,023)\end{array}$ & $\begin{array}{l}1,094^{* *} \\
(0,040)\end{array}$ & $\begin{array}{r}0,876^{* * *} \\
(0,018)\end{array}$ \\
\hline Região metropolitana & $\begin{array}{r}1,207^{* * *} \\
(0,056)\end{array}$ & $\begin{array}{r}0,791^{* * *} \\
(0,016)\end{array}$ & $\begin{array}{r}1,129 * * * \\
(0,043)\end{array}$ & $\begin{array}{r}0,845^{* * *} \\
(0,015)\end{array}$ & $\begin{array}{r}0,945 \\
(0,033)\end{array}$ & $\begin{array}{r}0,915^{* * *} \\
(0,017)\end{array}$ \\
\hline \multicolumn{7}{|c|}{ Região (Sudeste omitida) } \\
\hline Norte & $\begin{array}{l}0,839 * \\
(0,087)\end{array}$ & $\begin{array}{r}1,247^{* * *} \\
(0,050)\end{array}$ & $\begin{array}{r}0,712^{* * *} \\
(0,049)\end{array}$ & $\begin{array}{r}0,998 \\
(0,029)\end{array}$ & $\begin{array}{r}0,859 * * * \\
(0,047)\end{array}$ & $\begin{array}{r}0,840^{* * *} \\
(0,024)\end{array}$ \\
\hline Nordeste & $\begin{array}{r}1,355^{* * *} \\
(0,073)\end{array}$ & $\begin{array}{r}1,174^{* * *} \\
(0,031)\end{array}$ & $\begin{array}{r}1,193^{* * *} \\
(0,052)\end{array}$ & $\begin{array}{r}1,029 \\
(0,022)\end{array}$ & $\begin{array}{r}1,154^{* * *} \\
(0,047)\end{array}$ & $\begin{array}{r}0,859 * * * \\
(0,019)\end{array}$ \\
\hline
\end{tabular}

(continua) 
Tabela A1 (continuação)

\begin{tabular}{lrr|r|r|r|r}
\hline & 1993 & & 2005 & & 2015 \\
\cline { 2 - 7 } & $\begin{array}{r}\text { Sem } \\
\text { trabalho }\end{array}$ & $\begin{array}{r}\text { Todos } \\
\text { trabalham }\end{array}$ & $\begin{array}{r}\text { Sem } \\
\text { trabalho }\end{array}$ & $\begin{array}{r}\text { Todos } \\
\text { trabalham }\end{array}$ & $\begin{array}{r}\text { Sem } \\
\text { trabalho }\end{array}$ & $\begin{array}{r}\text { Todos } \\
\text { trabalham }\end{array}$ \\
\hline \multirow{2}{*}{ Sul } & $0,806^{* * *}$ & $1,375^{* * *}$ & 0,976 & $1,352^{* * *}$ & 1,046 & $1,285^{* * *}$ \\
& $(0,052)$ & $(0,037)$ & $(0,052)$ & $(0,033)$ & $(0,050)$ & $(0,032)$ \\
\hline \multirow{2}{*}{ Centro-0este } & 0,891 & 1,016 & 1,092 & $1,102^{* * *}$ & $0,822^{* * *}$ & $1,136^{* * *}$ \\
& $(0,070)$ & $(0,033)$ & $(0,065)$ & $(0,030)$ & $(0,047)$ & $(0,032)$ \\
\hline \multirow{2}{*}{ Intercepto } & $0,612^{* * *}$ & $2,492^{* * *}$ & $1,615^{* * *}$ & $3,560^{* * *}$ & $2,950^{* * *}$ & $4,404^{* * *}$ \\
& $(0,076)$ & $(0,141)$ & $(0,175)$ & $(0,185)$ & $(0,297)$ & $(0,255)$ \\
\hline $\mathbf{N}$ & & 58.808 & & 83.044 & & 81.157 \\
\hline
\end{tabular}

Fonte: Elaboração própria, a partir dos dados da PNAD, 1993-2015.

Nota: Desvios padrão entre parêntesis. Níveis de significância: ***1\%, ${ }^{*} 5 \%,{ }^{*} 10 \%$.

Tabela A2 Mulheres, 1993, 2005 e 2015

\begin{tabular}{lrrrrr|r|r}
\hline & & 1993 & & 2005 & & 2015 \\
\cline { 2 - 7 } & $\begin{array}{r}\text { Sem } \\
\text { trabalho }\end{array}$ & $\begin{array}{r}\text { Todos } \\
\text { trabalham }\end{array}$ & $\begin{array}{r}\text { Sem } \\
\text { trabalho }\end{array}$ & $\begin{array}{r}\text { Todos } \\
\text { trabalham }\end{array}$ & $\begin{array}{r}\text { Sem } \\
\text { trabalho }\end{array}$ & $\begin{array}{r}\text { Todos } \\
\text { trabalham }\end{array}$ \\
\hline Faixa etária (18-20 anos omitida) & & & & & \\
\hline \multirow{2}{*}{$21-23$} & $0,689^{* * *}$ & $1,093^{*}$ & $0,773^{* * *}$ & $1,192^{* * *}$ & 0,910 & $1,262^{* * *}$ \\
& $(0,072)$ & $(0,059)$ & $(0,065)$ & $(0,054)$ & $(0,078)$ & $(0,067)$ \\
\hline \multirow{2}{*}{$24-26$} & $0,562^{* * *}$ & $1,207^{* * *}$ & $0,601^{* * *}$ & $1,379^{* * *}$ & $0,673^{* * *}$ & $1,505^{* * *}$ \\
& $(0,059)$ & $(0,064)$ & $(0,051)$ & $(0,061)$ & $(0,060)$ & $(0,077)$ \\
\hline \multirow{2}{*}{$27-29$} & $0,613^{* * *}$ & $1,451^{* * *}$ & $0,620^{* * *}$ & $1,767^{* * *}$ & $0,709^{* * *}$ & $1,705^{* * *}$ \\
& $(0,063)$ & $(0,075)$ & $(0,053)$ & $(0,080)$ & $(0,060)$ & $(0,085)$ \\
\hline \multirow{2}{*}{$30-32$} & $0,636^{* * *}$ & $1,737^{* * *}$ & $0,670^{* * *}$ & $2,024^{* * *}$ & $0,688^{* * *}$ & $2,121^{* * *}$ \\
& $(0,066)$ & $(0,092)$ & $(0,057)$ & $(0,094)$ & $(0,060)$ & $(0,107)$ \\
\hline \multirow{2}{*}{$33-35$} & $0,831^{*}$ & $2,162^{* * *}$ & $0,706^{* * *}$ & $2,505^{* * *}$ & 0,927 & $2,700^{* * *}$ \\
& $(0,087)$ & $(0,116)$ & $(0,062)$ & $(0,117)$ & $(0,078)$ & $(0,135)$ \\
\hline \multirow{2}{*}{$36-38$} & 1,040 & $2,682^{* * *}$ & 1,039 & $3,007^{* * *}$ & 1,103 & $2,860^{* * *}$ \\
& $(0,110)$ & $(0,145)$ & $(0,090)$ & $(0,142)$ & $(0,093)$ & $(0,145)$ \\
\hline \multirow{2}{*}{$39-41$} & 1,183 & $2,457^{* * *}$ & 1,011 & $2,591^{* * *}$ & 1,088 & $2,601^{* * *}$ \\
& $(0,126)$ & $(0,136)$ & $(0,087)$ & $(0,121)$ & $(0,092)$ & $(0,132)$ \\
\hline \multirow{2}{*}{$42-44$} & $1,258^{* *}$ & $2,399^{* * *}$ & 1,102 & $2,421^{* * *}$ & 0,970 & $2,482^{* * *}$ \\
& $(0,137)$ & $(0,138)$ & $(0,096)$ & $(0,116)$ & $(0,083)$ & $(0,127)$ \\
\hline
\end{tabular}

(continua) 
Tabela A2 (continuação)

\begin{tabular}{|c|c|c|c|c|c|c|}
\hline & \multicolumn{2}{|r|}{1993} & \multicolumn{2}{|r|}{2005} & \multicolumn{2}{|r|}{2015} \\
\hline & $\begin{array}{r}\text { Sem } \\
\text { trabalho }\end{array}$ & $\begin{array}{r}\text { Todos } \\
\text { trabalham }\end{array}$ & $\begin{array}{r}\text { Sem } \\
\text { trabalho }\end{array}$ & $\begin{array}{r}\text { Todos } \\
\text { trabalham }\end{array}$ & $\begin{array}{r}\text { Sem } \\
\text { trabalho }\end{array}$ & $\begin{array}{r}\text { Todos } \\
\text { trabalham }\end{array}$ \\
\hline $45-47$ & $\begin{array}{r}1,435^{* * *} \\
(0,158)\end{array}$ & $\begin{array}{r}1,867^{* * *} \\
(0,114)\end{array}$ & $\begin{array}{r}0,891 \\
(0,078)\end{array}$ & $\begin{array}{r}1,815^{* * *} \\
(0,088)\end{array}$ & $\begin{array}{r}0,930 \\
(0,080)\end{array}$ & $\begin{array}{r}2,116^{* * *} \\
(0,109)\end{array}$ \\
\hline $48-50$ & $\begin{array}{r}1,520 * * * \\
(0,167)\end{array}$ & $\begin{array}{r}1,672^{* * *} \\
(0,107)\end{array}$ & $\begin{array}{r}1,133 \\
(0,098)\end{array}$ & $\begin{array}{r}1,615^{* * *} \\
(0,082)\end{array}$ & $\begin{array}{r}1,074 \\
(0,088)\end{array}$ & $\begin{array}{r}1,898^{* * *} \\
(0,098)\end{array}$ \\
\hline $51-53$ & $\begin{array}{r}1,851^{* * *} \\
(0,199)\end{array}$ & $\begin{array}{r}1,408^{* * *} \\
(0,096)\end{array}$ & $\begin{array}{r}1,412^{* * *} \\
(0,120)\end{array}$ & $\begin{array}{r}1,368^{* * *} \\
(0,073)\end{array}$ & $\begin{array}{r}1,117 \\
(0,091)\end{array}$ & $\begin{array}{r}1,554^{* * *} \\
(0,082)\end{array}$ \\
\hline $54-56$ & $\begin{array}{r}2,223^{* * *} \\
(0,231)\end{array}$ & $\begin{array}{r}1,092 \\
(0,079)\end{array}$ & $\begin{array}{r}1,499 * * * \\
(0,128)\end{array}$ & $\begin{array}{r}1,187^{* * *} \\
(0,068)\end{array}$ & $\begin{array}{r}1,502^{* * *} \\
(0,118)\end{array}$ & $\begin{array}{r}1,311^{* * *} \\
(0,072)\end{array}$ \\
\hline $57-59$ & $\begin{array}{r}2,320 * * * \\
(0,244)\end{array}$ & $\begin{array}{l}0,874^{*} \\
(0,071)\end{array}$ & $\begin{array}{r}1,839 * * * \\
(0,155)\end{array}$ & $\begin{array}{r}0,922 \\
(0,058)\end{array}$ & $\begin{array}{r}1,840^{* * *} \\
(0,144)\end{array}$ & $\begin{array}{r}1,052 \\
(0,061)\end{array}$ \\
\hline $60-62$ & $\begin{array}{r}2,779 * * * \\
(0,284)\end{array}$ & $\begin{array}{r}0,754^{* * *} \\
(0,064)\end{array}$ & $\begin{array}{r}2,224^{* * *} \\
(0,186)\end{array}$ & $\begin{array}{r}0,727^{* * *} \\
(0,050)\end{array}$ & $\begin{array}{r}2,329^{* * *} \\
(0,183)\end{array}$ & $\begin{array}{l}0,857^{* *} \\
(0,054)\end{array}$ \\
\hline $63-65$ & $\begin{array}{r}1,887^{* * *} \\
(0,214)\end{array}$ & $\begin{array}{r}0,612^{* * *} \\
(0,059)\end{array}$ & $\begin{array}{r}1,238^{* *} \\
(0,119)\end{array}$ & $\begin{array}{r}0,542^{* * *} \\
(0,043)\end{array}$ & $\begin{array}{r}1,407^{* * *} \\
(0,120)\end{array}$ & $\begin{array}{r}0,505^{* * *} \\
(0,037)\end{array}$ \\
\hline \multicolumn{7}{|c|}{ Anos de estudo (até 3 anos omitida) } \\
\hline 4 a 7 & $\begin{array}{r}0,814^{* * *} \\
(0,038)\end{array}$ & $\begin{array}{r}1,012 \\
(0,028)\end{array}$ & $\begin{array}{r}0,834^{* * *} \\
(0,035)\end{array}$ & $\begin{array}{r}1,066^{* *} \\
(0,031)\end{array}$ & $\begin{array}{r}0,718^{* * *} \\
(0,032)\end{array}$ & $\begin{array}{r}1,229^{* * *} \\
(0,047)\end{array}$ \\
\hline $8 \mathrm{a} 10$ & $\begin{array}{r}0,766^{* * *} \\
(0,049)\end{array}$ & $\begin{array}{r}1,043 \\
(0,036)\end{array}$ & $\begin{array}{r}0,734^{* * *} \\
(0,038)\end{array}$ & $\begin{array}{r}1,189^{* * *} \\
(0,038)\end{array}$ & $\begin{array}{r}0,644^{* * *} \\
(0,032)\end{array}$ & $\begin{array}{r}1,363^{* * *} \\
(0,053)\end{array}$ \\
\hline 11 a 14 & $\begin{array}{r}0,675^{* * *} \\
(0,042)\end{array}$ & $\begin{array}{r}1,577^{* * *} \\
(0,050)\end{array}$ & $\begin{array}{r}0,620^{* * *} \\
(0,029)\end{array}$ & $\begin{array}{r}1,597^{* * *} \\
(0,046)\end{array}$ & $\begin{array}{r}0,518^{* * *} \\
(0,023)\end{array}$ & $\begin{array}{r}1,665^{* * *} \\
(0,058)\end{array}$ \\
\hline 15 ou mais & $\begin{array}{r}0,593^{* * *} \\
(0,059) \\
\end{array}$ & $\begin{array}{r}2,594^{* * *} \\
(0,114)\end{array}$ & $\begin{array}{r}0,491^{* * * *} \\
(0,034)\end{array}$ & $\begin{array}{r}2,165^{* * *} \\
(0,077)\end{array}$ & $\begin{array}{r}0,368^{* * *} \\
(0,021)\end{array}$ & $\begin{array}{r}2,344^{* * *} \\
(0,089)\end{array}$ \\
\hline $\begin{array}{l}\text { Migrante } \\
\text { intermunicipal }\end{array}$ & $\begin{array}{r}0,954 \\
(0,037)\end{array}$ & $\begin{array}{r}1,019 \\
(0,022)\end{array}$ & $\begin{array}{l}0,946^{*} \\
(0,030)\end{array}$ & $\begin{array}{r}1,046^{* *} \\
(0,019)\end{array}$ & $\begin{array}{r}0,923^{* * *} \\
(0,027)\end{array}$ & $\begin{array}{r}1,056^{* * *} \\
(0,019)\end{array}$ \\
\hline Tamanho da família & $\begin{array}{r}0,521^{* * *} \\
(0,010)\end{array}$ & $\begin{array}{r}0,694^{* * *} \\
(0,006)\end{array}$ & $\begin{array}{r}0,415^{* * *} \\
(0,007)\end{array}$ & $\begin{array}{r}0,564^{* * *} \\
(0,005)\end{array}$ & $\begin{array}{r}0,393^{* * *} \\
(0,007)\end{array}$ & $\begin{array}{r}0,497^{* * *} \\
(0,005)\end{array}$ \\
\hline \multicolumn{7}{|c|}{ Razão de dependência familiar } \\
\hline Crianças & $\begin{array}{r}3,209 * * * \\
(0,113)\end{array}$ & $\begin{array}{r}2,129 * * * \\
(0,043)\end{array}$ & $\begin{array}{r}4,374^{* * *} \\
(0,137)\end{array}$ & $\begin{array}{r}2,613^{* * *} \\
(0,052)\end{array}$ & $\begin{array}{r}5,265^{* * *} \\
(0,183)\end{array}$ & $\begin{array}{r}3,184^{* * *} \\
(0,075)\end{array}$ \\
\hline Idosos & $\begin{array}{r}6,494 * * * \\
(0,410)\end{array}$ & $\begin{array}{r}1,988^{* * *} \\
(0,115)\end{array}$ & $\begin{array}{r}7,071^{* * * *} \\
(0,381)\end{array}$ & $\begin{array}{r}1,965^{* * *} \\
(0,095)\end{array}$ & $\begin{array}{r}6,979 * * * \\
(0,329)\end{array}$ & $\begin{array}{r}2,047^{* * * *} \\
(0,087)\end{array}$ \\
\hline
\end{tabular}

(continua) 
Tabela A2 (continuação)

\begin{tabular}{|c|c|c|c|c|c|c|}
\hline & \multicolumn{2}{|r|}{1993} & \multicolumn{2}{|r|}{2005} & \multicolumn{2}{|r|}{2015} \\
\hline & $\begin{array}{r}\text { Sem } \\
\text { trabalho }\end{array}$ & $\begin{array}{r}\text { Todos } \\
\text { trabalham }\end{array}$ & $\begin{array}{r}\text { Sem } \\
\text { trabalho }\end{array}$ & $\begin{array}{r}\text { Todos } \\
\text { trabalham }\end{array}$ & $\begin{array}{r}\text { Sem } \\
\text { trabalho }\end{array}$ & $\begin{array}{r}\text { Todos } \\
\text { trabalham }\end{array}$ \\
\hline $\begin{array}{l}\text { Família com } \\
\text { responsável mulher }\end{array}$ & $\begin{array}{r}2,744^{* * *} \\
(0,121)\end{array}$ & $\begin{array}{r}2,026^{* * *} \\
(0,053)\end{array}$ & $\begin{array}{r}2,173^{* * *} \\
(0,073)\end{array}$ & $\begin{array}{r}1,382 * * * \\
(0,027)\end{array}$ & $\begin{array}{r}1,726^{* * *} \\
(0,051)\end{array}$ & $\begin{array}{r}1,199 * * * \\
(0,022)\end{array}$ \\
\hline Região metropolitana & $\begin{array}{r}1,044 \\
(0,040)\end{array}$ & $\begin{array}{r}0,758^{* * *} \\
(0,016)\end{array}$ & $\begin{array}{r}1,001 \\
(0,032)\end{array}$ & $\begin{array}{r}0,810^{* * *} \\
(0,014)\end{array}$ & $\begin{array}{r}0,889 * * * \\
(0,026)\end{array}$ & $\begin{array}{r}0,893^{* * *} \\
(0,016)\end{array}$ \\
\hline \multicolumn{7}{|c|}{ Região (Sudeste omitida) } \\
\hline Norte & $\begin{array}{r}0,899 \\
(0,074)\end{array}$ & $\begin{array}{r}1,148^{* * *} \\
(0,047)\end{array}$ & $\begin{array}{r}0,755^{* * *} \\
(0,042)\end{array}$ & $\begin{array}{r}0,928^{* * *} \\
(0,027)\end{array}$ & $\begin{array}{r}0,955 \\
(0,044)\end{array}$ & $\begin{array}{r}0,754^{* * *} \\
(0,021)\end{array}$ \\
\hline Nordeste & $\begin{array}{r}1,357^{* * *} \\
(0,061)\end{array}$ & $\begin{array}{r}1,092^{* * * *} \\
(0,029)\end{array}$ & $\begin{array}{r}1,223^{* * *} \\
(0,044)\end{array}$ & $\begin{array}{r}0,975 \\
(0,021)\end{array}$ & $\begin{array}{r}1,194^{* * *} \\
(0,041)\end{array}$ & $\begin{array}{r}0,832^{* * *} \\
(0,018)\end{array}$ \\
\hline Sul & $\begin{array}{c}0,910^{*} \\
(0,048)\end{array}$ & $\begin{array}{r}1,410^{* * *} \\
(0,039)\end{array}$ & $\begin{array}{r}1,032 \\
(0,045)\end{array}$ & $\begin{array}{r}1,352^{* * *} \\
(0,033)\end{array}$ & $\begin{array}{r}1,112^{* * *} \\
(0,045)\end{array}$ & $\begin{array}{r}1,318^{* * *} \\
(0,033)\end{array}$ \\
\hline Centro-0este & $\begin{array}{r}0,860^{* *} \\
(0,056)\end{array}$ & $\begin{array}{r}0,971 \\
(0,032)\end{array}$ & $\begin{array}{r}1,082 \\
(0,053)\end{array}$ & $\begin{array}{r}1,031 \\
(0,028)\end{array}$ & $\begin{array}{r}0,976 \\
(0,046)\end{array}$ & $\begin{array}{l}1,062^{* *} \\
(0,030)\end{array}$ \\
\hline Intercepto & $\begin{array}{r}0,593^{* * *} \\
(0,64)\end{array}$ & $\begin{array}{l}0,895^{*} \\
(0,053)\end{array}$ & $\begin{array}{r}1,518^{* * *} \\
(0,140)\end{array}$ & $\begin{array}{r}1,858^{* * *} \\
(0,101)\end{array}$ & $\begin{array}{r}2,343^{* * *} \\
(0,220)\end{array}$ & $\begin{array}{r}2,070^{* * *} \\
(0,128)\end{array}$ \\
\hline $\mathrm{N}$ & & 62.198 & & 88.929 & & 88.732 \\
\hline
\end{tabular}

Fonte: Fonte: Elaboração própria, a partir dos dados da PNAD, 1993-2015.

Nota: Desvios padrão entre parêntesis. Níveis de significância: ***1\%, ${ }^{*}{ }^{*} \%$, *10\%.

Tabela A3 Homens e mulheres, 1993-2015

\begin{tabular}{|c|c|c|c|c|}
\hline & \multicolumn{2}{|r|}{ Homens } & \multicolumn{2}{|r|}{ Mulheres } \\
\hline & Sem trabalho & Todos trabalham & Sem trabalho & Todos trabalham \\
\hline \multicolumn{5}{|c|}{ Controlando por todas as outras variáveis } \\
\hline \multicolumn{5}{|c|}{ Ano (1993 omitido) } \\
\hline 1996 & $\begin{array}{l}1,072^{* *} \\
(0,033)\end{array}$ & $\begin{array}{r}0,955^{* * *} \\
(0,014)\end{array}$ & $\begin{array}{r}1,091^{* * *} \\
(0,028)\end{array}$ & $\begin{array}{r}0,959 * * * \\
(0,014)\end{array}$ \\
\hline 1999 & $\begin{array}{r}1,193^{* * *} \\
(0,035)\end{array}$ & $\begin{array}{r}0,951^{* * *} \\
(0,014)\end{array}$ & $\begin{array}{r}1,185^{* * *} \\
(0,030)\end{array}$ & $\begin{array}{r}0,938^{* * *} \\
(0,013)\end{array}$ \\
\hline 2002 & $\begin{array}{r}1,140^{* * *} \\
(0,033)\end{array}$ & $\begin{array}{c}1,035^{* *} \\
(0,014)\end{array}$ & $\begin{array}{c}1,141^{* * *} \\
(0,028)\end{array}$ & $\begin{array}{r}1,010 \\
(0,014)\end{array}$ \\
\hline 2005 & $\begin{array}{l}1,053^{*} \\
(0,030)\end{array}$ & $\begin{array}{r}1,122^{* * *} \\
(0,015)\end{array}$ & $\begin{array}{r}1,080^{* * *} \\
(0,026)\end{array}$ & $\begin{array}{r}1,068^{* * *} \\
(0,015)\end{array}$ \\
\hline
\end{tabular}

(continua) 
Tabela A3 (continuação)

\begin{tabular}{lrrrrr}
\hline & & Homens & & Mulheres \\
\cline { 2 - 5 } & Sem trabalho & Todos trabalham & Sem trabalho & Todos trabalham \\
\hline \multirow{2}{*}{2008} & 0,989 & $1,248^{* * *}$ & 1,036 & $1,134^{* * *}$ \\
& $(0,029)$ & $(0,017)$ & $(0,025)$ & $(0,015)$ \\
\hline \multirow{2}{*}{2011} & 1,025 & $1,189^{* * *}$ & $1,057^{* *}$ & $1,045^{* * *}$ \\
& $(0,030)$ & $(0,017)$ & $(0,026)$ & $(0,014)$ \\
\hline \multirow{2}{*}{2014} & 1,004 & $1,261^{* * *}$ & 1,008 & $1,064^{* * *}$ \\
& $(0,029)$ & $(0,017)$ & $(0,024)$ & $(0,015)$ \\
\hline \multirow{2}{*}{2015} & $1,131^{* * *}$ & $1,064^{* * *}$ & $1,081^{* * *}$ & $0,894^{* * *}$ \\
& $(0,033)$ & $(0,015)$ & $(0,026)$ & $(0,012)$ \\
\hline \multirow{2}{*}{ Intercepto } & $1,560^{* * *}$ & $3,190^{* * *}$ & $1,334^{* * *}$ & $1,652^{* * *}$ \\
\hline $\mathbf{N}$ & $(0,065)$ & $(0,067)$ & $(0,048)$ & $(0,035)$ \\
\hline
\end{tabular}

Fonte: Elaboração própria, a partir dos dados da PNAD, 1993-2015.

Nota: Desvios padrão entre parêntesis. Níveis de significância: ***1\%, **5\%, *10\%. 